Old Dominion University

ODU Digital Commons

Educational Foundations \& Leadership Theses

\& Dissertations

Spring 2012

\title{
Adult Learner Graduation Rates at Four U.S. Community Colleges By Prior Learning Assessment Status and Method
}

\author{
Milan S. Hayward \\ Old Dominion University
}

Follow this and additional works at: https://digitalcommons.odu.edu/efl_etds

Part of the Adult and Continuing Education Commons, Educational Methods Commons, and the Higher Education Commons

\section{Recommended Citation}

Hayward, Milan S.. "Adult Learner Graduation Rates at Four U.S. Community Colleges By Prior Learning Assessment Status and Method" (2012). Doctor of Philosophy (PhD), Dissertation, Educational Foundations \& Leadership, Old Dominion University, DOI: 10.25777/hmvh-6393

https://digitalcommons.odu.edu/efl_etds/120

This Dissertation is brought to you for free and open access by the Educational Foundations \& Leadership at ODU Digital Commons. It has been accepted for inclusion in Educational Foundations \& Leadership Theses \& Dissertations by an authorized administrator of ODU Digital Commons. For more information, please contact digitalcommons@odu.edu. 


\title{
ADULT LEARNER GRADUATION RATES AT FOUR USS. COMMUNITY COLLEGES BY PRIOR LEARNING ASSESSMENT STATUS AND METHOD
}

\author{
by
}

Milan S. Hayward

B.S. 1998, National-Louis University

M.S. 2006, Virginia Polytechnic Institute and State University

A Dissertation Submitted to the Faculty of

Old Dominion University in Partial Fulfillment of the

Requirement for the Degree of

DOCTOR OF PHILOSOPHY

COMMUNITY COLLEGE LEADERSHIP

OLD DOMINION UNIVERSITY

May 2012

Approved by:

MitcheltR-Willianhs (Director)

Steven P. Myran (Meriber)

$\overline{\text { Edward E. Raspiller (Member) }}$ 


\title{
ABSTRACT \\ ADULT LEARNER GRADUATION RATES AT FOUR U.S. COMMUNITY COLLEGES BY PRIOR LEARNING ASSESSMENT STATUS AND METHOD
}

\author{
Milan S. Hayward \\ Old Dominion University, 2012 \\ Director: Dr. Mitchell Williams
}

The college completion agenda demands improved graduation rates among adult learners and prior learning assessment (PLA) is a promising solution. PLA permits students to earn college credit for knowledge acquired outside of higher education and is associated with improved student outcomes. The current study expanded the literature regarding adult PLA learners in the community college by examining the graduation rates of adult learners in four U.S. community colleges by PLA status and method. Results confirmed significant difference in graduation rates between adult PLA learners and adult non-PLA learners, uncovered significant difference in the graduation rates of adult PLA learners by PLA method, and identified a significant relationship between PLA method and graduation. Findings provide policy makers, community college leaders, and adult educators with new insight into adult PLA learners in the community college, and provide a basis for future research leading to improved graduation among adult learners.

Keywords: adult learners, prior learning assessment, graduation rates, community colleges, completion agenda, PLA, ACE, CLEP, portfolios 
This dissertation is dedicated to Lauren, Jennifer, Matthew, Mark, and Christian and their respective needs to know, do, and become. Never stop learning. 


\section{ACKNOWLEDGEMENTS}

I gratefully acknowledge the members of my dissertation committee, Dr. Steven P. Myran and Dr. Edward E. Raspiller, for their insight and guidance in the development of this major adult learning project. I am especially thankful for the tireless support and counsel provided by my dissertation committee chair, Dr. Mitchell R. Williams. Your collective patience, assistance, and support for the current study are greatly appreciated.

The contributions of others were also critical to the success of the current study. I am thankful for the institutional researchers of Colleges A, B, C, and D, who sensed the value of the current study and graciously provided the necessary ex post facto data. In addition, I am grateful to Dr. Bruce Colletti, Dr. Shana Pribesh, and Ms. Kim Bullington Sibson, for generously sharing their respective statistical and editorial talents with me.

In a broader view of this work, I wish to recognize Harvey for sage advice; Sue, for introducing me to experiential learning; Marcie, for introducing me to adult learning; Bruce, for scholarly perspective; John, for trust; Bob, for mentorship; Mitch, for servant leadership; and Lauren, for patience and encouragement. Thank you all for walking with me, working with me, and modeling the best of what it means to be an adult educator. 
TABLE OF CONTENTS

\section{Page}

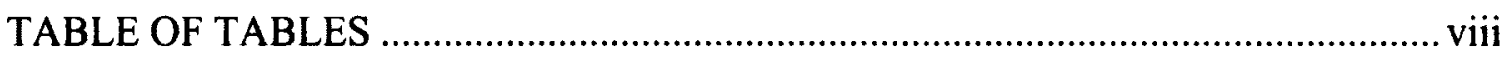

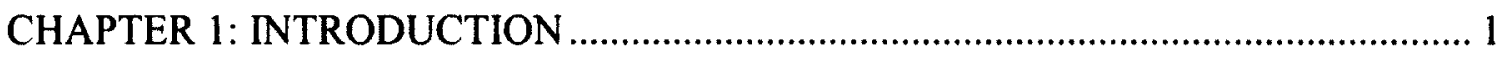

Study Background

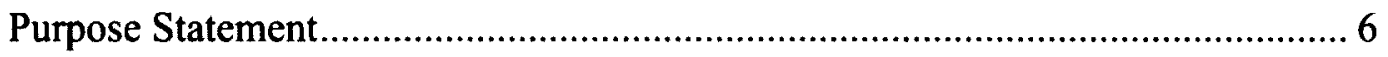

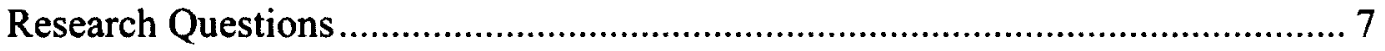

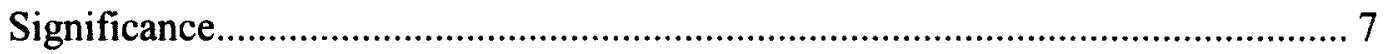

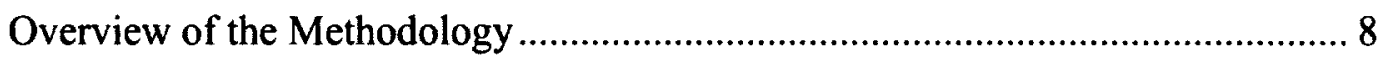

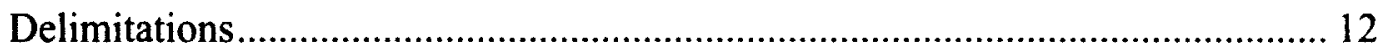

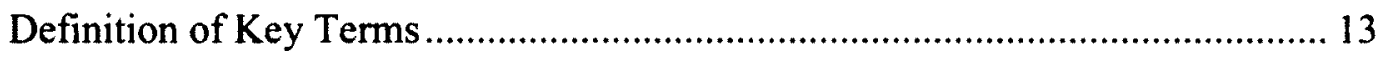

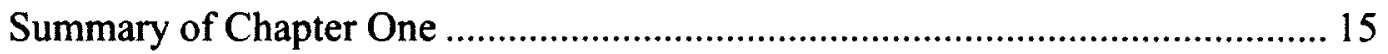

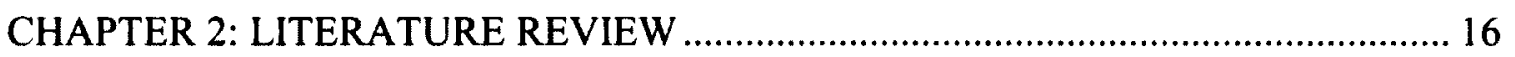

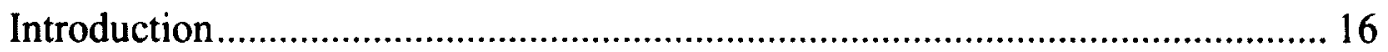

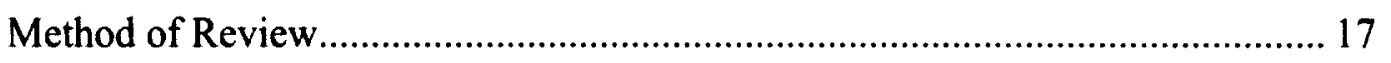

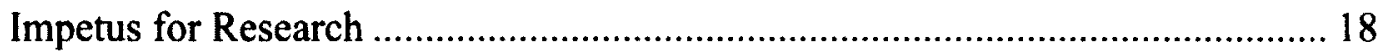

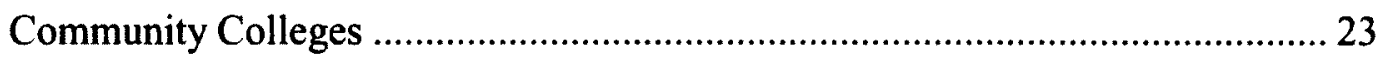

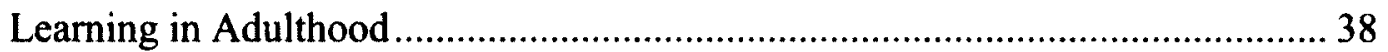

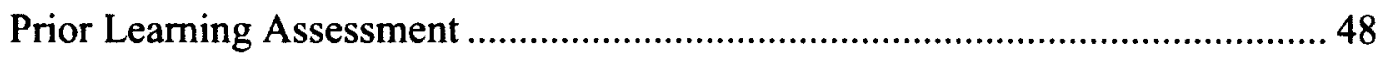

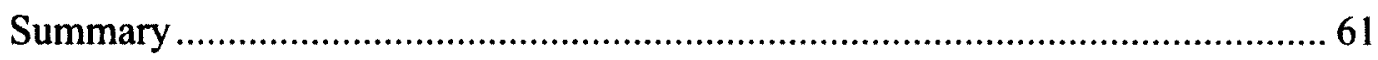

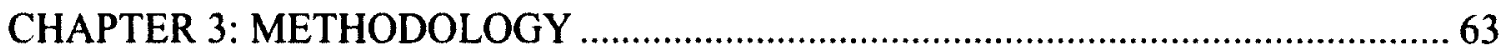

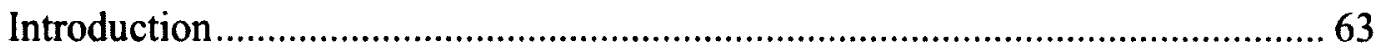

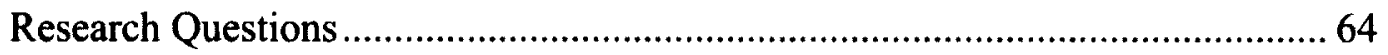




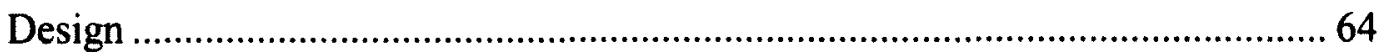

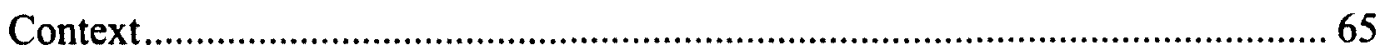

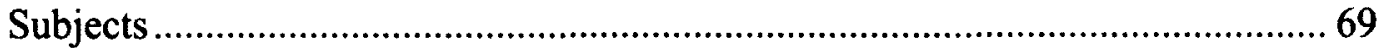

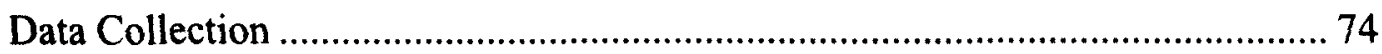

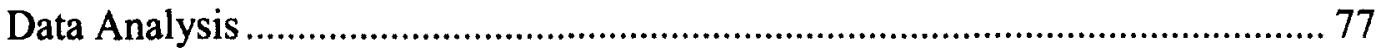

Assumptions and Limitations ...................................................................... 79

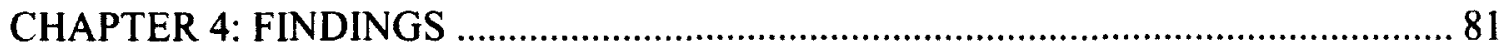

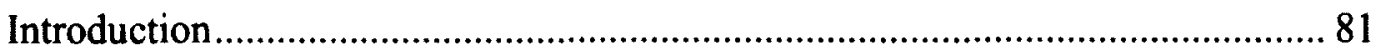

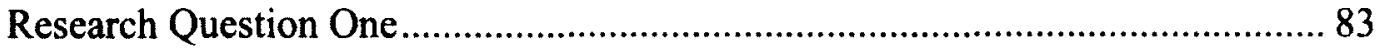

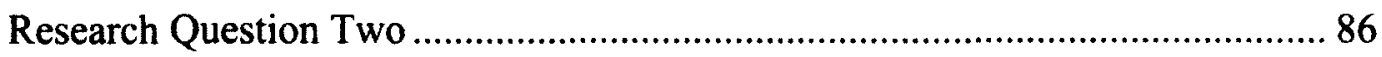

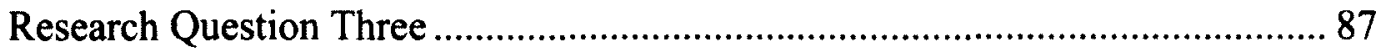

CHAPTER 5: CONCLUSIONS AND RECOMMENDATIONS .................................... 91

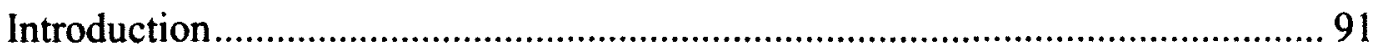

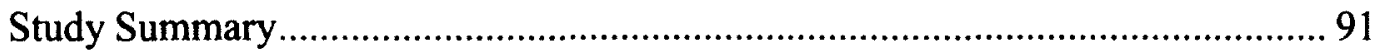

Findings and the Professional Literature ……………….................................... 99

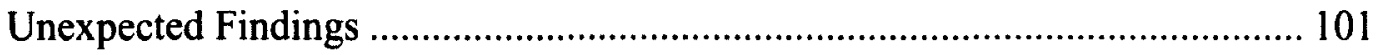

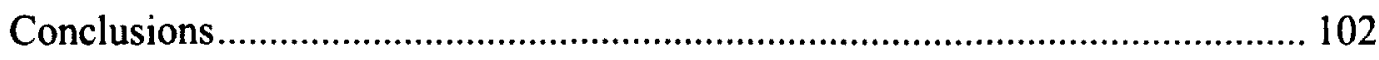

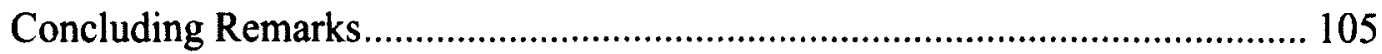

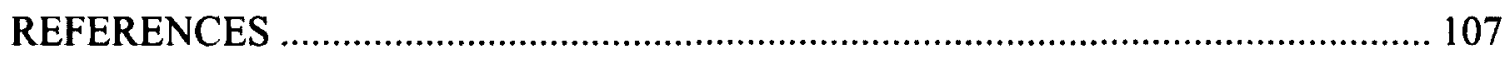

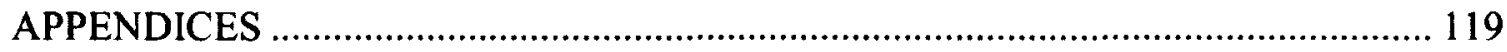

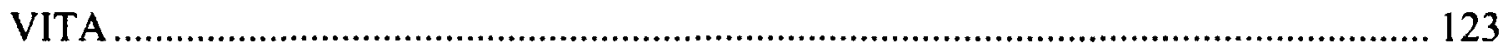


TABLE OF TABLES

Table

Page

3.1 Variable Table 69

3.2 Sample Distribution by PLA Status and College..................................................... 71

3.3 Sample Distribution by PLA Method and College …………................................. 71

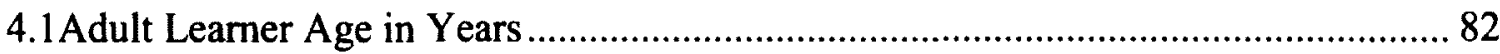

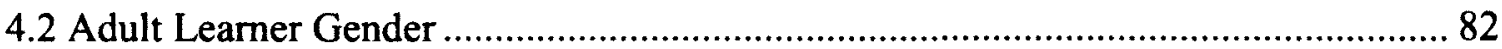

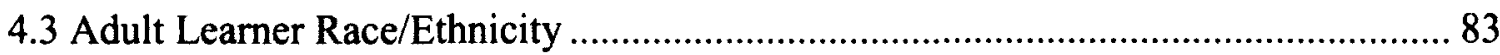

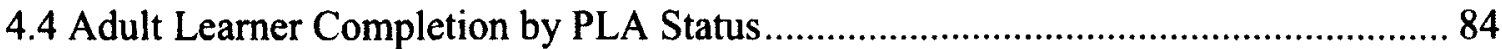

4.5 Adult Leaner Completion by PLA Status and College ……..................................... 85

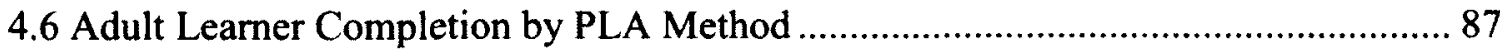

4.7 Classification Table: Prediction Success for Model $1 \ldots \ldots \ldots \ldots \ldots \ldots \ldots \ldots \ldots \ldots \ldots \ldots \ldots \ldots \ldots \ldots . . .88$

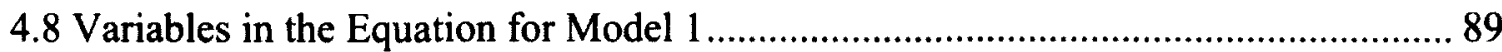

4.9 Classification Table: Prediction Success for Model 2 …......................................... 90

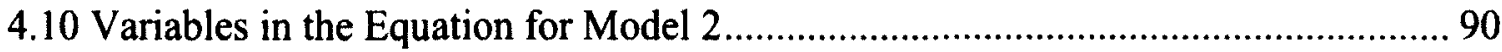




\section{CHAPTER 1}

\section{INTRODUCTION}

At the 2010 White House Summit on Community Colleges, President Obama noted the critical role community colleges should play in growing a highly developed workforce (Adams, 2010). With the United States falling behind other nations in proportion of college graduates, the president described the role of community colleges as essential to winning a global race to lead the growth industries of the 21 st century (Runningen \& Johnston, 2010). The White House indicated an additional five million community college graduates will be required to meet the president's graduation objective for 2020 (Mullin, 2010). The time has come for the ubiquitous community college mission to include college completion. Improved graduation rates among all college students are imperative to the economic vitality of the nation, including the millions of adult learners "seeking degrees in a system built largely for-and aroundtraditional students" (Pusser et al, 2007, p. 3).

According to Ritt (2008), the United States must meet the needs of a changing student population, a population Vaughan (2006) described as citizen students; students with adult responsibilities. Non-traditional students comprise a new majority in higher education, including $58 \%$ who are 22 years or older and $40 \%$ who are 25 years or older (Stokes, 2006). Non-traditional students are generally employed on a full or part-time basis, and have family and community responsibilities that affect the completion of educational goals. U.S. Secretary of Education Duncan suggested community colleges must learn to serve 28-year-old mothers who have work and family responsibilities (Adams, 2010). As policy makers and community college leaders study the challenge of 
increasing the number of graduates, the needs of adult learners must be a top consideration. Therefore, a study was conducted to examine a promising but underutilized means of promoting community college graduation among adult learners.

\section{Study Background}

\section{Perspective}

According to Dewey (1938), experience and education are intrinsically connected, particularly if education is to provide significant meaning to the learner. As institutions of higher learning have evolved to include open enrollment policies, the need has correspondingly increased to make learning relevant to life (Kolb, 1984).

Similarly, as the population in general grows older and the frequency of adult career change continues to increase, the "action" in higher education will be centered around adult learners who demand that the relevance and application of ideas be demonstrated and tested against their own accumulated experience and wisdom. (p. 6)

The meaningful and relevant application of learning is the promise of experiential learning. Institutions of higher learning may promote experiential learning through field activities, classroom exercises, and prior learning assessment (Lewis \& Williams, 1994).

\section{Overview of PLA}

Prior learning assessment (PLA) is a means by which college credit may be awarded for college level learning obtained outside of higher education (Freed \& Mollick, 2009). Knowles (1984) explained adults bring the sum of their lifelong experiences with them as adult learners. PLA recognizes the value of experience and acknowledges learning takes place in a variety of settings (Field, 1993). Credit may be 
awarded through a variety of means, including the acceptance of external college credit through articulation agreements and advanced standing for professional credentials. However, prior learning can also be assessed and credited for exam performance, the completion of evaluated programs, and by the evaluation of student portfolios (Lamdin, 1997). These last three methods helped define the independent variables in the study. The College Level Examination Program (CLEP) is an example of a college credit by examination program (Klein-Collins \& Hain, 2009). CLEP was founded in 1965 by the Educational Testing Service (ETS) to exempt students from college-level studies where competency could be established through examination. CLEP is commonly accepted by institutions of higher learning. Annually, "approximately 200,000 CLEP exams are administered at 1,300 testing centers across the nation" (Beaver \& Paul, 2007, p. 13). The exam saves students time and money, freeing them to focus on more challenging courses (The College Board, 2011). In a 2010 study of the availability of PLA in the community college, $90 \%$ of respondent institutions reported accepting CLEP scores for credit (Brigham \& Klein-Collins, 2010). The current study examined the graduation rates of adult learners who earned credit through CLEP.

Credit for the completion of evaluated training programs is another method of assessing prior learning. For example, the American Council on Education (ACE) evaluates workplace training (military and civilian) and makes credit recommendations for consideration by institutions of higher learning (Lamdin, 1997). ACE made its first college credit recommendations in regards to military training during World War II (Keeton, 2000). According to the ACE website, "the American Council on Education's College Credit Recommendation Service (CREDIT) connects workplace learning with 
colleges and universities by helping adults gain access to academic credit for formal courses and examinations taken outside traditional degree programs" (ACE, 2011, n.p.). Institutions are not obligated to accept ACE CREDIT recommendations, but are free to consider ACE student transcripts for college credit according to established institutional policies and practices (ACE, 2011). The current study examined the graduation rates of adult learners who earned ACE recommended credit.

Learning obtained through life experiences may also be evaluated for credit through the development and assessment of student portfolios. Portfolios are a unique form of PLA, providing adults with both a learning process and a means of demonstrating prior learning (Klein-Collins \& Hain, 2009). Suopis (2009) described portfolio development as an analytical method of validating experiential learning. Most portfolios share four common elements: (a) the identification of specific learning students seek to have recognized as creditable, (b) a narrative describing the learning experience and how it is connected to student plans, (c) documentation supporting student claims, and (d) a request for a specific amount of college credit (Lamdin, 1997). Suopis (2009) explained, "PLA has consistently embraced the student's ability to document experiential learning through a critical and reflective analysis that we believe is best rendered through the writing of a portfolio" (Suopis, 2009, p. 125). The current study examined the graduation rates of adult learners who earned credit for the successful completion of PLA portfolios.

\section{PLA Student Success}

The Council for Adult and Experiential Learning (CAEL) surveyed 48 institutions of higher learning in 2010. CAEL found PLA students experienced greater success than non-PLA students as measured by time to degree, persistence toward degree for non- 
degree earners, and graduation rates. For example, PLA community college students who earned between 13 and 24 PLA credits earned an associate degree in 4.5 fewer months on average than students with no PLA credit. Although many students in the study received no degree over a 7-year period, PLA students generally amassed more credits toward their degree program than non-PLA students. More important, "PLA students in this study had much higher degree-earning rates than non-PLA students. More than half (56\%) of PLA students earned a postsecondary degree within seven years, while only $21 \%$ of non-PLA students did so" (Council for Adult and Experiential Learning, 2010, p. 7). Results were reported in aggregate, not by PLA method.

\section{PLA Program Utilization}

Klein-Collins and Hain (2009) noted the use of portfolio development and assessment increased from 50\% in 1991 to $66 \%$ in 2006 among respondent institutions of higher learning. Despite this increase and the association between PLA students and improved student outcomes, portfolio development and assessment is not offered in as many community colleges as credit by examination or credit for evaluated programs. A study of PLA in community colleges found $64 \%$ of respondent colleges offered student portfolio assessments, while $82 \%$ considered ACE recommendations (credit for evaluated programs) and $90 \%$ accepted CLEP credit (credit by examination) (Brigham \& KleinCollins, 2010). Further, Brigham and Klein-Collins acknowledged PLA is generally underutilized at community colleges that purportedly recognize or award PLA credit.

The scarcity of current literature regarding PLA in the community college suggests PLA-related decisions may be made without clear understanding of the potential benefit to students. Researchers have studied the benefits of PLA methods in aggregate, 
but few have identified study results by specific PLA method. Little was known regarding the relationship, if any, between PLA method and graduation. Studies have included the graduation rates of learners in higher education, but few have focused on adult learners in the community college. The question for community college leaders is, "How effectively do we deliver on our mission and make a distinctive impact, relative to our resources?" (Collins, 2005, p. 5). Therefore, an exploratory study was conducted of adult learner graduation rates at four U.S. community colleges, by PLA status (PLA or no PLA) and method (ACE, CLEP, Portfolio, and Combination). As a result, a clearer picture is emerging in regard to adult PLA learner graduation in the community college.

\section{Purpose Statement}

The purpose of the quantitative study was to examine adult learner graduation rates by prior learning assessment (PLA) status and method at four U.S. community colleges. The exploratory study tested the statistical significance of differences in graduation rates between adult PLA and non-PLA learners in four U.S. community colleges, tested the statistical significance of differences in graduation rates between adult PLA learners by method, and examined the relationship between adult PLA learner graduation and PLA method. Graduation rate was described as the percentage of students who earned an associate degree within 4 years. Associate degrees include the Associate of Arts (A.A), Associate of Science (A.S.), Associate of Applied Science (A.A.S.), and similar 2-year degrees, as typical for U.S. community colleges. 


\section{Research Questions}

The study was guided by the following three questions:

1. What is the difference in graduation rates between adult non-PLA learners and adult PLA learners at four U.S. community colleges?

2. What is the difference in graduation rates between adult PLA learners by PLA method at four U.S. community colleges?

3. Is there a relationship between adult PLA learner graduation and PLA method at four U.S. community colleges, controlling for age, gender, and race/ethnicity?

\section{Significance}

The impetus for the current study was the college completion agenda, or the need to graduate increased numbers of college students. According to the U.S. Department of Education (2010), graduation among first-time full-time students attending public 2-year colleges was only $12 \%$ in 2 years and $28 \%$ in 4 years. However, "the attention given to this group of students obscures the fact that the vast majority of college and university students are 'non-traditional'-largely working adults struggling to balance jobs, families, and education" (Stokes, 2006, p. 1). Unfortunately, even the modest graduation rates among first-time full-time students may appear unachievable for part-time community college students with adult responsibilities. Nevertheless, if President Obama's goal of 5 million additional community college graduates by 2020 is to be achieved, and if more Americans are to be prepared to participate in the new knowledgebased economy, adult learners must graduate in increasingly higher numbers. 
However, a significant increase in adult learner graduation rates is not likely to occur without consideration of the needs of adult learners. Therefore, the goal of the current study was to examine a promising form of experiential learning which has demonstrated utility in promoting student success, in alignment with the adult need for meaningful and relevant applied learning. The intended audience for the current study is the group of policy makers, community college leaders, and adult educators seeking scalable solutions to low community college graduation rates among adult learners. Few studies have examined PLA programs in the community college and little is known about graduation rates among adult PLA learners by method. The significance of the study is its potential to alert community college stakeholders to the unique needs of adult learners through an emergent understanding of adult learner graduation by PLA status and method. Current study results should shape future research and contribute to data-driven decisions, leading to improved community college graduation rates among adult learners.

\section{Overview of the Methodology}

\section{Type}

Quantitative research methods provide for the analysis of numerical data for the purpose of examining relationships between variables (Creswell, 2009). Consequently, quantitative methods were used to meet the objectives of the current study's three research questions. Typical of ex post facto research, current study participants were identified by characteristics they already possess (Sprinthall, 2007). Because the data concerned variable interactions which may have already occurred, the research strategy for the current study can be classified as ex post facto. 


\section{Sampling}

The settings for the current study were four U.S. community colleges which purported to offer or accept at least two of the three prior learning assessment (PLA) methods under study; credit by examination, credit for evaluated programs, and portfolio development and assessment. A particular emphasis was placed on finding institutions offering portfolio development and assessment, since data was expected to be less abundant for portfolio learners. Non-probability sampling took place at the institutional level since the population of community colleges actively offering or accepting PLA credit was unknown, as was the population of adult PLA learners within U.S. community colleges (Plano Clark \& Creswell, 2010). Selection of participant colleges was affected by the researcher's ability to identify and communicate with eligible colleges, the interest of institutional stakeholders, and their ability to identify and collect the necessary data. Four East-Coast community colleges (A, B, C, and D) were included in the study.

To encourage consistency in results across institutions by PLA method, credit earned through the College Level Examination Program (CLEP) was used to represent credit by examination. American Council on Education (ACE) recommendations for workplace training represented credit for evaluated programs. Credit earned through local portfolio programs (Portfolio) represented portfolio learning. CLEP and ACE data were expected in greater abundance than portfolio data. To help ensure a testable sample, participant colleges were asked to provide census data for two student cohorts (2004/2005 and 2005/2006). The two cohorts were followed for four academic years each. Four years was selected as twice the period in which first-time full-time students 
might be expected to earn an associate degree (U.S. Department of Education, 2010), because adult learners are more likely to be part-time students (Horn \& Nevill, 2006). Adult students were defined as 25 years of age or older the year they became placed in an associate degree program (declared a major). The ages of 24 and 25 are commonly regarded or utilized in the literature as the minimum ages of non-traditional students (Hadfield, 2003; Stokes, 2006; U.S. Department of Education, 2006), and 25 is well beyond the commonly accepted age range of 18-22 for traditional students (Stokes, 2006; U.S. Department of Education, 2006). The idea was to test a group, as Knowles (1984) suggested, whose quantity and variety of experience lent itself to experiential learning techniques. Adult learner age, gender, race/ethnicity, and veteran status were requested in addition to graduation data. Demographic data were collected to help describe study participants and begin to control for potentially confounding variables. Data collection began officially in late September 2011 and ended in January 2012.

\section{Analysis}

In the early stages of study planning, parametric tests such as $t$ tests, a one way analysis of variance (ANOVA), and linear regression were planned as the means of data analysis. In fact, parametric testing conducted as unofficial points of reference signaled remarkable results. A Sheffe Post Hoc test indicated clear and noteworthy differences in adult PLA learner graduation rates between specific PLA methods. However, Charles and Mertler (2002) indicated parametric tests are used to analyze normal distributions. Given the number of colleges, the small number of Portfolio and Combination participants, and proportionately different numbers of PLA students among participant colleges, no assumptions of normality were made for the distributions. 
Although nonparametric tests are less sensitive to minute differences in data than parametric measures, Sprinthall (2007) indicated nonparametric tests may be used without regard to the normality of the distribution. Therefore, non-parametric tests of proportions were conducted for research questions one and two, supported by chi-square analysis. Logistic regression (also nonparametric) was utilized to answer research question three, since the regression model included a categorical dependent variable (graduation). Nonparametric measures seem most appropriate for this early study of adult PLA learner graduation rates by PLA method. However, findings suggest the need for careful study on a broader scale with more generalizable results. Parametric instruments may be preferable in future studies wherein larger data distributions may be assumed to be normal and graduation rates may be collected as continuous data.

IBM SPSS Statistics software version 19 was used to analyze the data. An initial test of frequencies was utilized to describe adult learners in the study by age, gender, race/ethnicity, and veteran status. However, veteran status was not reported in the current study due to low response rate. To answer research question one, a hypothesis test of proportions was conducted to examine the graduation rates of adult learners by PLA status, followed by a chi-square test of homogeneity. To answer research question two, a hypothesis test of proportions was conducted to examine adult PLA learner graduation rates by PLA method, followed by a chi-square test of homogeneity.

Research question three was addressed by creating and evaluating two logistic regression models. First, Model 1 tested the ability of PLA method (independent variable) to predict adult PLA learner graduation (dependent variable) in comparison to the baseline model (Model 0 ) generated by the software. Second, Model 2 tested the 
combined ability of PLA method, adult PLA learner age, gender, and race/ethnicity (independent variable), to predict PLA learner graduation in comparison to Model 1. Differences were observed between the models, particularly in regard to the impact of demographics on model prediction. Hosmer-Lemeshow Test results were used to indicate the goodness of fit of each logistic regression model.

\section{Delimitations}

The following delimitations apply to the current study:

- The first limiting step of the current study was the selection of research topic. Many related studies might be conducted regarding adult PLA learners in the community college, but the current study was considered foundational.

- The current quantitative study examined ex post facto data according to the variables identified in the methodology section. The researcher disaggregated the data by age, gender, race/ethnicity, and veteran status as able.

- The results of the current non-experimental study can be said to demonstrate a mathematical relationship between variables, not causation.

- The current study focused on adult learners at four U.S. community colleges. The census of U.S. community colleges offering the PLA methods under study was unknown. Therefore, the study results are not known to actually represent the total population of all qualifying institutions.

- The current study examined adult learner graduation in regard to associate degrees, not any other kind of community college degree or certificate. 
- The current study included students who were placed in a degree program (declared a major), suggesting student intent to earn an associate degree. The study did not attempt to identify reasons for lack of degree attainment.

- The current study did not follow the degree completion of students who transferred to another institution during the period under study.

\section{Definition of Key Terms}

- Adult learners: For the purposes of the current study, adult learners are described as 25 years or older the year they were placed in an associate degree program (declared an academic major).

- American Council on Education (ACE): Referred to as ACE throughout the study, this organization evaluates workplace training (military and civilian) and makes credit recommendations available for consideration by institutions of higher learning (Lamdin, 1997). See credit for evaluated programs.

- Associate degree: For purposes of the current study, associate degrees include the Associate of Arts (A.A), Associate of Science (A.S.), Associate of Applied Science (A.A.S.) Degrees, and similar 2-year degrees, as typical for U.S. community colleges.

- College Level Examination Program (CLEP): Referred to as CLEP throughout the study, this popular credit by examination program (Donlon, 1991) was founded in 1965 by the Educational Testing Service (ETS) to provide student exemptions for college level studies where competency could be established by examination (Beaver \& Paul, 2007). 
- Council for Adult and Experiential Learning (CAEL): Referred to as CAEL throughout the study, this is "a national, non-profit organization whose mission is to expand learning opportunities for adults" (CAEL, 2011, n.p.).

CAEL sponsors and disseminates research on the topic of prior learning assessment (PLA) as part of its mission.

- Credit by examination: Credit by examination is a common method of assessing the prior learning of students in higher education (Lamdin, 1997). Credit by examination means "credit is awarded for a successful, meets-thecriterion performance regardless of what manner of preparation was used" (Donlon, 1991, p. 2).

- Credit for evaluated programs: Credit for the successful completion of evaluated military and civilian training programs is one method of assessing prior learning (Lamdin, 1997). ACE evaluated programs and credit recommendations are a common example of credit for evaluated programs.

- Portfolio development and assessment: For the current study, use of the term "portfolio development and assessment," or related terms such as "portfolio development," "portfolio assessment," or "portfolios," refers to a method of evaluating experiential learning through the use of student portfolios.

- Prior learning assessment (PLA): PLA allows college credit to be awarded for college-level learning obtained outside institutions of higher learning (Freed \& Mollick, 2009). The current study included three specific PLA methods. 


\section{Summary of Chapter One}

A national imperative demands an increase in community college graduation rates among adult learners. Scalable solutions are needed to support the unique needs of adult learners. Prior learning assessment (PLA) recognizes the value of prior and experiential learning obtained in a variety of settings. Credit by examination, credit for evaluated programs, and portfolio development and assessment are common methods of evaluating prior learning. According to Brigham and Klein-Collins, "students with PLA credit had higher graduation rates, better persistence and lower time to degree, compared to students without PLA credit" $(2010$, p. 1). Given the impetus of the completion agenda and the unique needs of adult learners, an exploratory study was conducted to examine the graduation rates of adult learners in four U.S. community colleges by PLA status and method. Results can be used to inform data-driven decisions by public policy makers and to guide future research, leading to improvements in adult learner graduation rates. 


\section{CHAPTER 2}

\section{LITERATURE REVIEW}

\section{Introduction}

Improved graduation rates among all college students are imperative to the economic vitality of the nation, including the millions of adult learners "seeking degrees in a system built largely for-and around—-traditional students" (Pusser, et al., 2007). According to Ritt (2008), the U.S. must meet the needs of a changing student population, a population Vaughan (2006) described as citizen students, or students with adult responsibilities. As policy makers and community college leaders study the challenge of increasing the number of graduates, the needs of adult learners must be a top consideration. "Institutions around the country are creating policies and programs to encourage more adult learners to earn degrees or certificates, but without a more aggressive approach, reaching President Obama's college-completion goal for the nation will prove difficult" (Gonzales, 2011, n.p.).

The goals of this review of literature were to identify (a) the college completion agenda, (b) the related roles of community colleges, (c) philosophical perspectives of learning in adulthood, and (d) a potential tool for promoting college graduation among adult learners. The review began with the impetus for the study: a discussion of the U.S. degree completion agenda, current graduation rates, and call for action. The call for action led to a review of the responsibility of community colleges to increase graduation rates among the large numbers of adult learners who are part-time students. Next, the literature helped identify the context and roles of self-direction and experience in successful adult learning activities. Finally, the review addressed the growing practice of 
prior learning assessment (PLA) in higher education, and its potential as a solution to the completion agenda among adult learners in the community college.

\section{Method of Review}

The review of professional literature depended on commercially available books, and journal articles retrieved through electronic university library databases. Books regarding the role of experience in learning, adult learning theory, and related philosophical perspectives were typically written by learning theorists and adult educators. Books directly related to prior learning assessment (PLA) were often published or supported in some way by the Council for Adult and Experiential Learning (CAEL), a non-profit organization devoted to promoting adult learning opportunities. Most of the books referenced in the literature review were acquired through major online book retailers. Some of the books were out of print and were obtained via used book resellers affiliated with a major online book retailer.

Old Dominion University (ODU) libraries provided a significant means of retrieving articles through electronic databases. The Virginia Polytechnic Institute and State University (Virginia Tech) Library Summon system was useful for topics where professional literature appeared less abundant and more difficult to locate. ERIC and EBSCO databases were often used to search for articles by keywords. Search terms included "experiential learning AND community colleges", "prior learning experience", "prior learning experience AND community colleges", "portfolio development and assessment", "portfolios AND community colleges", "credit by examination", "CLEP”, "credit by evaluated programs", "ACE recommended credit", "community college graduation rates", and other related search terms. CAEL's website was a source for non- 
juried PLA publications. Literature contents and reference lists also helped identify additional subtopics and sources included in the following review of literature.

\section{Impetus for Research}

\section{Completion Agenda}

At the 2010 White House Summit on Community Colleges, President Obama noted the critical role community colleges should play in growing a highly developed workforce (Adams, 2010). Suggesting the U.S. is behind other nations in proportion of college graduates, the President described the role of community colleges as essential to winning a global race to lead the growth industries of the 21 st century (Runningen \& Johnston, 2010). This was not the first time the President alluded to the nation's slippage in international rankings of education attainment, nor to its effect on the national economy. In 2009, Mr. Obama challenged U.S. higher education to produce 8.2 million more graduates by 2020 . According to the President, five million of the additional graduates must come from community colleges (Mullin, 2010). Demand for a worldclass workforce and the cost of higher education in a bad economy has shifted responsibility for graduating students to community colleges (Cooper, 2010). The time has come for the traditional community college mission of open enrollment to turn toward and include college completion (Mullin, 2010).

Mullin (2010) noted a two-part community college completion agenda: increased education attainment to improve international ranking, and improved preparation and placement for the nation's workforce. Bosworth (2008) explained the connection between education attainment and the economic vitality of the country. According to the author, workforce productivity rose in previous decades as younger workers entering the 
workforce were largely better educated than existing and exiting workers. This "made a substantial contribution to economic growth and rising productivity-as much as 20 to $25 \%$ of overall labor productivity growth, according to some estimates" (Bosworth, 2008, p. 73). The productivity dynamic has leveled off in recent years and may have declined based on changing demographics and stagnant graduation rates. Smaller cohorts of incoming workers with historically lower rates of academic achievement will not outweigh the future loss of a larger number of better educated workers (Bosworth, 2008).

Additional job and education forecasting is required because of the widespread effects of gross miscalculations on government policy and supporting activities (Carnevale, Smith, \& Strohl, 2010). Nevertheless, Carnevale et al. (2010) support a completion agenda because the pending national economic recovery will depend on positions requiring skilled labor. According to the authors, $63 \%$ of job openings will require personnel with some college education by 2018 . "By 2018 we end up with a shortfall of workers with Associate's degrees or better of about 3 million. At current rates, degrees conferred would have to increase by about $10 \%$ a year to eliminate the shortfall —or the economy would need to slow its demand for higher education in its workers" (Carnevale et al., 2010, p. 18). Lost and declining industries will require workforce training for new jobs in other industries (Gilroy, 2010) and adults who used to fill positions requiring low skills are at risk for being left behind in a renewed knowledge-based economy (Camevale et al., 2010).

The broad goal of increased national degree attainment implies a call for action. Organizers of the 2010 White House Summit said achievement of the President's 2020 graduation goal demands collaboration among community college stakeholders, such as 
community college and business leaders, in order to produce an additional five million graduates. Others suggested the need for greater alignment and collaboration between community colleges and industry (Adams, 2010). In a meeting following the Summit, U.S. Secretary of Education Duncan asserted increasing graduation rates will require change in the way higher education fulfills its mission (Gonzales, 2011). According to Bosworth, "there must be far greater emphasis on new and improved education technology in order to build and articulate demand, to deliver instruction, to measure progress, and to test for competency" (2008, p. 79$)$.

Non-governmental stakeholders are beginning to mobilize. For example, in cooperation with five other associations, the chair of the American Association of Community Colleges (AACC) announced a forthcoming initiative to improve community college completion rates (Jaschik, 2010). In addition, the senior program officer for the Bill and Melinda Gates Foundation explained the organization wishes to accelerate systemic change, leading to increased community college completion rates (Jaschik, 2010). The Lumina Foundation also has a plan to "increase the number of Americans with two- or four-year college degrees from $39 \%$ to $60 \%$ by 2025 " (Gilroy, 2010, n.p.). The Lumina plan asserts students must be prepared for post-secondary education, the capacity of higher education should be increased through increased productivity, and higher education graduation rates must dramatically improve (Gilroy, 2010).

Suggestions for shaping public policy abound and "any conversation about national educational attainment goals is also a conversation about national priorities" (Mullin, 2010). Templin (2011) indicated community colleges will need additional resources to meet national graduation goals and AACC outlined a 10-step legislative 
agenda, including $\$ 12$ billion in federal support for community colleges through grants and increased Pell Grant funding (Cooper, 2010). In contrast, Neal McCluskey of the Cato Institute's Center for Educational Freedom, cautioned outspending other countries on higher education has not provided the U.S. with commensurate outcomes (Gilroy, 2010). Bosworth (2008) suggested demand-side incentives to motivate employees and employers to invest more in post-secondary education is a better use of resources than directly funding providers of post-secondary education. He also suggested replacing the under-performing federal basic education program with a workforce-based model.

\section{Graduation Rates}

The way institutions measure graduation rates is governed by the Student Rightto-Know and Campus Security Act (Pub. L. No. 101-542) (Bailey, Crosta, \& Jenkins, 2006). The 1990 law amended the Higher Education Act of 1965 (Pub. L. No. 89-329), requiring institutions to report graduation rates to the federal government as a condition of participating in the federal financial aid program. Right-to-Know rates are based on institutional cohorts consisting only of full-time, first-time, degree-seeking college students. Rates are determined by dividing the number of cohort graduates in a reporting period by the number of students in the cohort and reported as a percentage (Bailey et al., 2006). Right-to-Know rules permit $150 \%$ of the time normally assumed to complete a degree program. Therefore, colleges offering associate (2-year) degrees have 3 years to measure degree completion (Bailey et al., 2006). For example, a cohort of associate degree-seeking students which graduated 50 of 100 students in 3 years would report a graduation rate of 50\%. Beginning in 2008, the U.S. Department of Education also began 
collecting graduation rates at $200 \%$ of the normal time, or 4 years for 2 -year degree completion (U.S. Department of Education, 2010).

Right-to-Know rates are reported to the National Center for Education Statistics (NCES) (Bailey, et al., 2006), which is responsible for collecting and analyzing U.S. education data (NCES, 2010). According to NCES, the total 2002 bachelor's degreeseeking cohort graduated at the rate of $57.2 \%$ (Aud et al., 2011). Within the total rate are varying rates by student gender and institution type. For example, females attending private not-for-profit universities graduated within 6 years at more than three times the rate of females attending private for-profit institutions (66.7\% to $20.5 \%)$. Males in the 2002 bachelor's degree-seeking cohort generally graduated at lower rates than females. Overall, the total 6-year bachelor's degree graduation rate was $59.7 \%$ for females compared to the total rate of $54.1 \%$ for males (Aud et al., 2011).

NCES also analyzed and posted graduation data regarding public and private 2year institutions (Aud et al., 2011). The private institutions were distinguished as either not-for-profit or for-profit (NCES, 2010). The public institutions are probably community colleges, institutions Vaughan (2006) described as mainly public colleges which offer the associate (2-year) degree. The total graduation rate for the 2005 cohort of students seeking both certificates and associate degrees within a $150 \%$ timeframe was $27.5 \%$. Remarkably, the rate of $57.7 \%$ at private, for-profit 2 -year institutions, slightly topped the aforementioned bachelor degree-seeking graduation rate. However, the graduation rate for public 2-year institutions was $20.6 \%$ (Aud et al., 2011), far less than the rates of for-profit and not-for-profit private institutions in the 2-year category. 


\section{Community Colleges}

\section{Mission}

The first community college was Joliet Junior College (Boone, 1997; Reitano, 1998).

The founding of Joliet Junior College was important because it demonstrated the feasibility and desirability of using tax dollars to establish institutions of higher education in the community, with the needs of the community helping to shape the courses and programs offered by those community-based institutions. (Boone, 1997, p. 3)

Junior colleges, the community college of the early $20^{\text {th }}$ century, were initially an extension of the high school, providing the first 2 years of university study (Bragg, 2001; Cohen \& Brawer, 2008). The missions of the community college have been shaped over time by diverse and competing demands within society. The missions may be stated as well as implied through programmatic offerings (Dougherty \& Townsend, 2006).

Community colleges serve about half of all U.S. undergraduates, making them a critical entry point into post-secondary education for students with no prior college education (Bailey et al., 2006; Choy, 2002).

Today's community college is deeply embedded in the fabric of its community by virtue of its founding legislation, mission, funding base, and achievements. It can rightly lay claim to being labeled the people's college. Its program offerings are comprehensive and embrace every aspect of living. (Boone, 1997, p. 5)

Reitano likened urban community colleges to land-grant universities, making educational opportunities available to many who could not otherwise access higher education (1998). 
Access and service to the community are themes within the broad mission of the modern community college (Boone, 1997). Associated activities make the community college America's most democratic institution of higher learning (Laanan, 2001).

A significant role of the community college is the democratization of higher education for all Americans who have an interest in and can benefit from higher education (Bragg, 2001). Supporting this role of democratization is the overarching community college mission of open access, particularly to those who could not attend college due to barriers related to income and academic preparation (Zeidenberg, 2008). As Vaughan (2006) explained, open enrollment does not permit students to enroll in academic programs regardless of preparation, but provides a way for underprepared students to qualify for college level study. Access to higher education implies more than an open enrollment policy and includes "having a college within commuting distance of most residents and giving students choices in what they study" (Vaughan, 2006, p. 4). Access is also related to access to future economic opportunity (Bailey \& Morest, 2006). Access to higher education may be viewed as a framework for community colleges, under which individual missions are often separately pursued (Reitano, 1998). The purpose of the modern community college is to strengthen the communities they serve through a wide array of educational programs and services (Vaughan, 2006). The mission is considered comprehensive-including the delivery of university preparation and transfer education, vocational education, developmental education, and continuing education/community service (Vaughan, 2006). Dougherty and Townsend (2006) identified almost identical mission components as occupational education, university transfer education, remedial education, and continuing education/adult 
education/community services. Reitano (1998) described a similar four part mission as "compensatory, career, community, plus the collegiate or transfer function" (p. 125).

\section{Developmental Education}

Unfortunately, many students are not prepared for college-level study and enroll in community college for the opportunity to qualify through developmental education programs (Mellow \& Heelan, 2008; Vaughan, 2006). The terms remedial, developmental, and compensatory education, are used to describe the academic and life skills coursework necessary for less prepared students to succeed at the college level (Cohen and Brawer, 2008). Shaw (2001) indicated remedial education is pre-college coursework at the post-secondary education level, while developmental education is a holistic approach combining personal and academic development. "In addition to content-based coursework, developmental education programs may also offer tutoring, study skills courses, and counseling" (Shaw, 2001, p. 195). Specific uses of the terms by other authors support this description (Cohen \& Brawer, 2008; Mellow \& Heelan, 2008).

Developmental education seeks to support students who are not prepared for college level work because of poverty, uneducated parents, or other circumstances, and provide them with the essential literacy and numeracy skills to begin college level studies (Mellow \& Heelan, 2008). A significant number of students in higher education take remedial courses in mathematics and English, and the load is greatest in the community college (Zeidenberg, 2008). For example, "in the fall of $2000,42 \%$ of first-year students at 2-year public schools enrolled in at least one remedial course, compared with $20 \%$ at public 4-year schools and 12\% at private 4-year schools" (Zeidenberg, 2008, p. 53). Although remediation is not new to higher education, Cohen and Brawer (2008) 
explained, "the decline in achievement exhibited by secondary school graduates and dropouts in the 1970s hit the colleges with full force. The problem of the marginal student became central to instructional planning" (p. 290).

\section{University Preparation}

Community colleges had two primary missions from the beginning: university transfer education and workforce development (Dougherty \& Townsend, 2006; Fonte, 2011). However, university preparation and transfer was the primary purpose of the first community colleges (Boone, 1997; Mellow \& Heelan, 2008; Reitano, 1998). University preparation and transfer was important for students who were unable or unwilling to leave home to attend college, and for those who were not accepted by the college of their choice (Mellow \& Heelan, 2008). "The great majority of the nation's community colleges offer transfer programs through which students can complete the first two years of college" (Vaughan, 2006, p. 9). According to Mellow and Heelan (2008), community colleges play the role of preparing millions of students for baccalaureate study by providing the first 2 years of college.

Associate and baccalaureate degree-granting institutions each offer the first 2 years of a baccalaureate program (Ignash \& Townsend, 2001), and articulation agreements make college credits transferable from one institution to another (Vaughan, 2006). Acceptance by universities is perhaps the oldest issue in the community college, as evidenced by the time and attention spent articulating what courses and degrees universities will accept toward the completion of the baccalaureate (Cohen and Brawer, 2008). The completion of university transfer and vocational education programs may each result in the bestowal of an associate degree, but the focus of the collegiate function 
is on the liberal arts, not career skills (Cohen \& Brawer, 2008). "Students enrolled in transfer programs take courses almost identical to those they would take in a bachelor's degree program at a four-year college or university. Most of the courses are in the humanities, mathematics, sciences, and social sciences" (Vaughan, 2006, p. 9).

Cohen and Brawer (2008) referred to teacher education and other university transfer programs as $2+2$ programs. The $2+2$ means the community college provides the equivalent of the first 2 years of a baccalaureate program, while a 4-year institution provides the last 2 years of the program and bestowal of the bachelor's degree. Ultimately, "community colleges are expected to serve as an integral part of a larger, statewide educational pipeline, yielding baccalaureate graduates through their transfer links with four-year institutions" (Ewell, 2011, p. 25). Nonetheless, students do not always transfer in a unidirectional fashion from community colleges to 4-year institutions. Reverse transfer students move from 4-year institutions to community colleges, while swirlers transfer between a number of associate and baccalaureate degreegranting institutions (lgnash \& Townsend, 2001; Mellow \& Heelan, 2008).

\section{Occupational Education}

Workforce development in the community college is focused on the provision of occupational education (Dougherty \& Townsend, 2006). Despite the university transfer orientation of early community colleges, occupational or vocational education was also included to a lesser extent (Cohen \& Brawer, 2008).

Junior colleges limited their occupational programs to teacher training, office skills, and the agricultural sciences. Over time, many of these programs evolved into baccalaureate programs and have been replaced at community colleges by 
programs in fields as diverse as early childhood education, office management, laser optics, medical and computer technologies, auto body repair, and fire science. (Vaughan, 2006, p. 9)

The terms occupational, technical, terminal, and vocational education appear interchangeably in the literature and share preparation of students for employment as a common purpose (Cohen \& Brawer, 2008; Gordon, 2003; Vaughan, 2006). Gordon (2003) explained vocational education and applied technology education prepare students for employment in positions requiring less than a baccalaureate degree, while programs in occupational education may extend to the baccalaureate and graduate levels. References to terminal education are no longer used and implied employment education with no potential for baccalaureate study (Cohen \& Brawer, 2008).

Community college academic programs are broadly divided into groups by degree focus areas (Mellow \& Heelan, 2008). Associate of arts (A.A.) degrees in occupational fields such as early childhood education and associate of sciences (A.S.) degrees in fields such as nursing are designed to transfer to 4-year institutions. Associate of applied arts (A.A.A.) or associate of applied science (A.A.S.) degrees typically prepare students for immediate employment and are less transferrable to baccalaureate programs (Mellow \& Heelan, 2008). However, technical programs aligned with workforce needs are needed more than additional bachelor degrees in some regions of the country (Fonte, 2011).

Expansion of vocational education in the community college during the late $20^{\text {th }}$ century was facilitated in part by employer demand for post-secondary training and the growth of modern technologies (Cohen and Brawer, 2008). "Community colleges left behind their 'junior college' status when they began to provide students with vocational, 
paraprofessional, and technical degrees and certificates" (Mellow \& Heelan, 2008, p. 218). Occupational programs are developed with the dual purpose of meeting industry demand for skilled labor by preparing students for employment, and program advisory committees are established to help manage these symbiotic interests (Cohen \& Brawer, 2008). Ideally, community colleges serve as a bridge between students and industry, by hiring qualified faculty who are current in their fields and delivering educational programs in alignment with current workforce standards (Mellow \& Heelan, 2008). The Link program at Gateway Technical College (Knudson, 2004) exemplified how occupational education programs can meet the needs of both students and industry.

\section{Continuing Education}

Non-credit workforce development programs are another critical component of the community college mission (Mellow \& Heelan, 2008). Non-credit educational programs are often confused with the traditional academic offerings of an institution (Wang, 2004). However, non-credit workforce development courses and programs make it possible for potential and current employees to obtain the skills and acquire the credentials employers require (Mellow \& Heelan, 2008) without concern for traditional college schedules, course credits, or grades. "Non-credit programs can sequence progressively educational milestones of increasing difficulty in short spurts to allow lowincome adults to more easily achieve academic goals, progressive levels of employment, and incremental increases in hourly pay" (Mellow \& Heelan, 2008, p. 229). Community colleges also provide customized credit or non-credit training to suit the needs of a particular business (Cohen \& Brawer, 2008; Mellow \& Heelan, 2008; Vaughan, 2006). 
Continuing (non-credit) education, like traditional credit programs, is one way community colleges contribute to the lifelong learning of community residents (Vaughan, 2006). Often free of oversight by governing boards (Vaughan, 2006), continuing education programs are the most elastic community college functions, permitting colleges to respond quickly to a wide range of specific community training needs (Mellow \& Heelan, 2008; Vaughan, 2006). Some authors placed continuing education courses under a broader framework they call community education (Cohen \& Brawer, 2008; Wang, 2004). Regardless of nomenclature, non-credit educational programs in the community college include continuing education, adult education, and community services (Cohen \& Brawer, 2008; Dougherty \& Townsend, 2006; Wang, 2004). The classification of this array of courses is college specific. For example, some colleges deem GED (general education diploma) preparation a form of adult education (Cohen \& Brawer, 2008; Wang, 2004) and others view it as workforce development (UDC Community College, 2012).

\section{Non-Traditional Students}

College students were once considered traditional if they enrolled in postsecondary education directly after high school, worked part time or not at all, and depended financially on their parents (Choy, 2002). However, the vast majority of all current college undergraduates (2-and 4-year institutions) fall under one or more of the old characteristics attributed to non-traditional learners (Choy, 2002). Secretary of Education Duncan referred to non-traditional students as $21^{\text {st }}$-century students since nontraditional students are now the standard (Adams, 2010). Several characteristics contribute to the description of non-traditional students, including (a) financially independent of parents, (b) part-time status, (c) delayed enrollment, (d) worked full time, 
(e) had dependents, (f) single parent, and (g) no high school diploma (Choy, 2002). Nontraditional students comprise a new majority in higher education, including $58 \%$ who are 22 years or older and $40 \%$ who are 25 years or older (Stokes, 2006).

Community colleges have always attracted more non-traditional students than their 4-year counterparts (Bragg, 2001). However, almost 90\% of the students at 2-year (public and private) institutions had one or more characteristic normally attributed to nontraditional learners (Choy, 2002). In particular, community college students are older adults than their counterparts in the university (Bragg, 2001). According to Horn and Nevill (2006), slightly more than half (53\%) of community college students were age 24 and older, with $35 \%$ of the population composed of students age 30 years or older. Further, community colleges mostly serve students who are age 24 or older and can be described as financially independent of their parents (Horn \& Nevill).

Non-traditional students are generally employed on a full- or part-time basis, and have family and community responsibilities that affect the completion of educational goals (Adams, 2010). "Indeed, community colleges tend to serve students who, because of family, work, or other responsibilities, are only able to attend on a part-time basis" (Horn \& Nevill, 2006, p. 21). According to Aud et al. (2011), the majority of students in public 2-year institutions were enrolled part-time during the fall 2009 semester, including $61 \%$ of students age 25 to 34 , and $63 \%$ of students age 35 years and older. Unfortunately, a part-time tempo is rarely successful because of the lengthened time to degree and the number of priorities competing for time in the life of a working adult (Bosworth, 2008). Indeed, Choy (2002) found "among those seeking an associate's 
degree, $62 \%$ of highly nontraditional students left without any degree, compared with $19 \%$ of traditional students" (pp. 12-13).

"All institutions have not one 'student body' but many, and community colleges tend to have the greatest diversity in this respect" (Ewell, 2011, p. 30). In addition to age, community college students are also more likely to be women, minorities, and have family responsibilities (Bragg, 2001). Boone (1997) indicated women were the new majority and the American Association of Community Colleges (AACC) reported approximately $32 \%$ of community college students belong to a minority group (AACC, 2012). Bragg (2001) recognized African American and Hispanic students as a larger proportion of the student population at 2-year institutions than at 4-year institutions. However, Bragg made a distinction between non-traditional and minority status, suggesting non-traditional status has more to do with age and dependency than racial or ethnic characteristics. Choy's (2002) seven characteristics of non-traditional students lend support to this observation.

Community college students are often the first in their family to attend college and unfamiliar with the programs and learning resources available in their new educational environment (Nomi, 2005; Zeidenberg, 2008). Indeed, a significant community college population are first generation students: those whose parents have no postsecondary education (Nomi). The author cited the National Center for Education Statistics (NCES), indicating first generation students comprise $45 \%$ of the total community college population. As a group, "first-generation community college students are more racially and ethnically diverse than are their peers" (Nomi, 2005, p. 3). A 
slightly higher percentage of minority students reported being first-generation students, rather than having parents who attended at least some college.

As in the general population of community college students, Nomi (2005) noted the non-traditional student age and adult responsibilities of first-generation students. "First-generation community college students are more likely to be women, older than traditional college age, employed full time, and to support dependents living at home" (Nomi, 2005, p. 1). The median age of first-generation community college students is 24 years, in contrast to 21 years for students whose parents attended at least some college (Nomi, 2005). "First-generation community college students tend to take fewer credit hours each semester and to face greater financial problems and family responsibilities" (Nomi, 2005, p. 2). First generation students are more likely to work full time but live in households with substantially less income. Students in one survey cited cost as a reason for attending community college over a 4-year institution, while more first generation students as a proportion indicated cost was very important (Nomi, 2005).

In concluding this section on community college students, Gilroy's (2010) awareness of race as an underlying issue behind completion is noteworthy. "This issue has taken on growing importance as the proportion of the population from groups traditionally underrepresented in higher education grows rapidly" (p. 20). Completion rate by race is a reasonable concern since minority students are overrepresented in remedial courses (Shaw, 2001). Nevertheless, the review of literature focused on what the overwhelming number of non-traditional community college students have in common. Community college students are typically adults over 24 years old, are generally employed on a full- or part-time basis, and have family and community 
responsibilities that affect the completion of educational goals (Adams, 2010; Aud et al., 2011; Horn \& Nevill, 2006). They also seek formalized learning for a variety of reasons, and are often out of formal education for years at a time (Hadfield, 2003).

\section{Accountability}

"Increasingly, states are using graduation and job-placement rates, among other measures, to judge the performance of their colleges and universities. Several states, including Arkansas and South Carolina, have begun tying state appropriations to how well public colleges meet prescribed goals, including how fast they graduate their students" (Burd, 1997, n.p.). Questioning the success of public institutions with high drop-out rates, private college president Turan implied the use of graduation rates to measure return on investment is reasonable. James Appleberry of the American Association of State Colleges and Universities disagreed, asserting the quality of higher education should not be legislated (Burd, 1997). Historically, community college leaders tended to agree with Appleberry (Jaschik, 2010), in part because Right-to-Know graduation cohorts are not necessarily representative of an institution's general student population. For example, first-time, full-time, degree-seeking college students are rarely adult learners with family responsibilities (Bailey et al., 2006).

Nevertheless, "funding formulas are being reexamined. Financial aid is shifting from grants to loans. Questions of productivity and efficiency are being raised" (Levine, 2001, p. 39). Further, "in the past couple of years, federal interest in community college performance has increased markedly. The Obama administration's ambitious access goal of matching global attainment rates of $60 \%$ of a young adult age cohort with a college credential by 2025 will fall disproportionately on the nation's community college sector" 
(Ewell, 2011, pp. 25-26). Federal and state governments are significant community college stakeholders (Ewell, 2011). For instance, state funding may be lower for community colleges than for public 4-year institutions, but state contributions have generally comprised a greater proportion of community college funding. Even federal government funds are directed to community colleges through federal student aid. In a sense, the federal government also oversees community colleges through the nongovernmental agencies it authorizes to accredit educational institutions (Ewell, 2011).

\section{Challenges}

The growing diversity of the community college student population has significantly contributed to a diversity of community college missions (Bragg, 2001). This multiplicity added to confusion about what community colleges do and appropriate measures of student and institutional outcomes. Complicating matters are what Bragg (2001) described as the evolution and integration of these missions, leading to less recognizable outcomes. For example, vocational studies were once considered terminal, or intended to lead only to employment. However, vocational students in the modern community college apparently have a greater need or interest in occupational programs that can facilitate transfer to 4-year institutions as necessary (Bragg, 2001; Gordon, 2003). Community colleges are unique institutions fulfilling a number of missions. As a result, standard success measures such as graduation rates cannot adequately gauge the effective fulfillment of the college's various roles (Ewell, 2011).

The literature indicated conflict between the missions of the comprehensive community college (Bragg, 2001; Dougherty \& Townsend, 2006; Mellow \& Heelan, 2008). Expanding and sometimes conflicting roles and missions of community colleges 
are the result of diverse student interests and purposeful decisions by public policymakers (Bragg, 2001). Conflict is representative of divisions within society and may not be eliminated through refining the mission scope as long as a number of interests are not addressed, such as academic excellence, open access, and workforce development (Dougherty \& Townsend, 2006). For instance, occupational programs are more expensive than university transfer programs and less likely to transfer. Cost might not matter to occupational students or faculty, but may impact the role and success of institutional focus on university transfer (Dougherty \& Townsend, 2006).

Mellow and Heelan (2008) recognized the open access focus of the community college as a dichotomous ideal. Community colleges have a democratizing effect on access to higher education (Bragg, 2001) and a reputation for students dropping out at a greater rate than comparable students in 4-year institutions (Reitano, 1998). Community colleges face substantial challenges in unprepared students, declining public financing, and a high dropout rate. The huge number of students participating in remedial education is discouraging to students and a drain on public (and student) resources (Bragg, 2001). Fonte (2011) cautioned an open door policy with no restrictions can develop a numbers bubble, based on large sums of students requiring remedial work with little likelihood of graduation. Templin (2011) summarized by saying, "community colleges are the most likely sector of higher education to expand, especially among low-income and minority populations, but they cannot achieve our national goals unless significant reforms are adopted to improve student achievement" (p. 9). 


\section{Opportunity}

According to Boone (1997), the community college should play the role of leader and catalyst for community change. He described an increased public dependency on government for solutions in recent decades and asserted the community college can be an institution around which communities gather to find answers to local challenges. Boone listed community ties, political neutrality, multidisciplinary resources, and a focus on education as some of the underpinnings for this vision. He credited community colleges with past success, hinting at the potential for future progress:

Community colleges, in their quick and relevant response to the nation's workforce preparedness needs, are responsible for preparing a sizable number of the nation's workforce for entry into the workplace. Further, these colleges are looked to by the nation's employers as a primary source for retooling and keeping the nation's workforce up-to-date. Indeed, the health of the nation's economy can be largely attributed to the leadership of the nation's community colleges in economic development. (p. 5)

Reitano (1998) noted opportunities in the areas often considered challenges or excuses by community college stakeholders. For instance, citing high course failure rates and limited empirical research, Shaw (2001) indicated the short and long term effects of remediation were uncertain at best. However, by 2008 "an initial examination of courses in Florida.... found a positive correlation between taking these courses and outcomes such as degree completion and transfer to a 4-year institution, although a causal relationship was not established" (Zeidenberg, 2008, p. 57). Cohen and Brawer (2008) suggested integrated or holistic developmental programs (not just remedial courses) 
demonstrated some success in promoting college progress among remedial students. Although studies have supported integrating academic and social activities to promote student success, the number of hours worked and family responsibilities may be greater predictors of success among older, working, adult learners (Bragg, 2001).

The way to address the problem of a less educated future workforce is to serve the needs of the millions of less educated adults in the current workforce (Bosworth, 2008; Klein-Collins, Sherman, \& Soares, 2010). "In 2006, there were about 120 million adults aged 25 to 64 in the active labor force [however] about 62 million adult workers lack a post-secondary credential of any kind" (Bosworth, 2008, p. 74). This massive pool of less educated adults represents a significant opportunity for the country (Bosworth, 2008). As policymakers and community college leaders study the challenge of increasing the number of graduates, the needs of adult learners must be a top consideration (Gonzales, 2011). "Institutions around the country are creating policies and programs to encourage more adult learners to earn degrees or certificates, but without a more aggressive approach, reaching President Obama's college-completion goal for the nation will prove difficult" (Gonzales, 2011, n.p.).

\section{Learning in Adulthood}

\section{Background}

Liberal education is the oldest educational philosophy in the Western world (Merriam \& Brockett, 2007). Liberal educators viewed its purpose as the development of an informed and cultured society, through a study of philosophy, fine arts, ancient languages, and religion. Hoerner (1970) attributed liberal education to the ancient Greeks and indicated learning included the rights and responsibilities of citizenship. Delors 
(1998) might refer to liberal education as learning to know. "As a means it serves to enable each individual to understand at the very least enough about his or her environment to be able to live in dignity.... As an end, its basis is the pleasure of understanding, knowing, and discovering" (Delors, 1998, pp. 86-87).

Liberal education was a dominant philosophy in the United States until the "mid$19^{\text {th }}$ century" (Merriam \& Brockett, 2007, p. 33), even for the education of adults. Forms of liberal education philosophy are still evident in liberal arts colleges and liberal arts programs in higher education (Merriam \& Brockett, 2007). According to Lindeman (1926), liberal education revolved "around non-vocational ideals" (p. 5) and was disconnected with the requirements of life for most people. Hoerner (1970) agreed and suggested the students of early liberal education, free men of the upper class, had little need for vocational education. Despite the pervasiveness of liberalism, others promoted a citizenry "able to use what they know, to have the capacity for critical analysis, and to be equipped for lifelong learning" (Lindeman, 1926, p. 24).

Over time, progressivism emerged as a consequence of national movement from an agrarian to an industrial society, and with the growing awareness and influence of the scientific method (Merriam \& Brockett, 2007). Pragmatism was the impetus for progressivism, where personal observation and experience could challenge liberal thought. Progressivism is known to adult educators as, "a focus on learners and their needs and experiences rather than on predetermined content. The use of scientific methodology incorporating problem-solving, activity, and experience-based approaches to instruction. A shift from teacher as authority figure to teacher as facilitator of learning. Education as an instrument of social action and social change" (Merriam \& Brockett, 
2007, p. 36). Delors (1998) might describe progressivism as learning to do; not simply task-related skills, but a broader skill set that includes social considerations, particularly the relationship skills required of growing service economies.

Humanism has similar origins to liberal philosophy and emerged in contrast to the behaviorists' "deterministic perspective of human behavior" (Merriam \& Brockett, 2007, p. 40). Humanistic assumptions include freedom to choose, a self-determinant nature, and capacity to grow and develop. The capacity and potential of humankind to grow and change is a well-known theme among adult educators (Merriam \& Brockett, 2007) and the essence of learning to be (Delors, 1998). Learning to be includes the development of the self, its various intelligences, senses, and values. Humanism is a learner-centered educational philosophy, which affects both attitudes and knowledge, or affective and cognitive domains (Merriam \& Brockett, 2007). Other philosophical perspectives are represented in the broad field of adult education today, including transformational, critical, and feminist theories (Merriam \& Caffarella, 1999).

Early research on learning in adulthood focused on the question of whether adults could learn (Merriam, 2001). Studies often compared the test performance of adult learners to younger learners, not why, when, or how adults learn. It was not until the late 1920 s when research was published concerning the ability of adults to learn (Merriam, 2001; Penland, 1977). Once humans were determined to be capable of learning in adulthood, the question turned toward the nature of adult learning. Merriam (2001) observed this change in emphasis after the professionalization of adult learning as a movement and wrote, "the need to develop a knowledge base unique to adult education, 
was the context in which two of the field's most important theory-building effortsandragogy and self-directed learning-emerged" (p. 4).

\section{Andragogy}

Andragogy was developed from humanist and progressive ideals (Merriam \& Brockett, 2007) and is the best known framework for understanding the needs of adult learners (Merriam, Caffarella, \& Baumgartner, 2007). Merriam (2001) explained pedagogy can be defined as teacher-centered instruction, while andragogy is more learner centered. According to Merriam et al. (2007), Knowles' andragogical model originally included four positions: (a) individuals progress from dependence toward self-direction as they mature, (b) experience is a rich and growing learning resource, (c) adult readiness to learn is related to the responsibilities of his or her developmental level, and (d) adults are more concerned with solving problems than with subjects. Later, Knowles (1984) included, (e) internal motivators are more effective than external, and (f) adults need to know why they must learn what they are invited or required to learn.

Pratt (1993) questioned whether adult learners are able to actively construct knowledge and process learning from experience. However, Knowles (1984) was careful how he defined adults and explained the term adult has legal, biological, and social connotations. Knowles (1984) indicated individuals psychologically become adults when they accept responsibility for their decisions; the most important consideration in regard to adult learners. Nevertheless, Knowles' (1984) view of andragogy as the antithesis of pedagogy softened over time. In later years, he described a learning continuum dependent on teacher direction on one end, and andragogy, or student direction, on the other end (Knowles, 1984; Merriam, 2001). Achievement of certain learning objectives 
may necessitate learner dependence on the instructor, as in the pedagogical model. However, Knowles (1984) asserted the andragog "will do everything possible to help the learners take increasing responsibility for their own learning" (p. 63).

Adult education focuses on instructing adults in formal and non-formal settings, while adult learning seeks to enable an increase of knowledge on topics of interest to the learner (Cross, 1978). Adult learners desire learning relevant to their lives and do not want to waste time on prescribed learning activities (Cross; Knowles, 1984). Therefore, Cross and others asserted adult educators should collaborate with adult learners on how and what they learn (Knowles, 1984; Tough, 1978). Adult learners are "motivated primarily by the desire to solve immediate and practical problems. They are interested not so much in storing knowledge for use at some future time as in applying knowledge to life goals that seem important to them" (Cross, 1978, p. 5). Adults do not have time to take a class every time they need to make a decision (King, 2010; Penland, 1977). "As such, the phenomenon of adult learning becomes a wider and more universal phenomenon than adult education" (Penland, 1977, p. 16).

\section{Context}

The literature suggested learning occurs within a variety of contexts (Cross, 1978; Marsick \& Watkins, 2001; Mocker \& Spear, 1982; Penland, 1977; Tough, 1978). There are four general frameworks for learning; formal, non-formal, informal, and self-directed (Mocker \& Spear, 1982; Penland, 1977). Merriam and Caffarella (1999) noted the same four contexts, but used the terms informal and self-directed learning interchangeably. Mocker and Spear (1982) explained the contexts in which learning takes place can be evaluated along a continuum representing locus of control. The more control someone 
other than the learner exercises over how and what is learned, the greater the formality of the learning context. Substituting formal and informal contexts for pedagogy and andragogy as the boundaries of an adult learning continuum, Mocker and Spear's (1982) focus on learner control appears similar to Knowles' (1984) observations.

Formal learning was described by Tough (1978) as the tip of the iceberg, or the most visible $20 \%$ of adult learning projects. Formal learning takes place in association with institutions such as colleges, vocational schools, and the military (Mocker \& Spear, 1982), as well as libraries, businesses, or other organizations which provide training or educational activities (Merriam \& Caffarella, 1999). One common factor among these institutions is the instruction they provide supports their respective missions (Merriam \& Caffarella, 1999). However, the greatest indicator of formality is institutional control (Mocker \& Spear, 1982). For example, decisions about program course requirements, or how and when courses are delivered are generally made within the sponsoring institution. A student decision to take a course in a classroom instead of through distance learning technologies does not change program ownership (Mocker \& Spear, 1982).

Non-formal learning is generally provided in communities for the purpose of addressing social concerns (Merriam \& Caffarella, 1999). From the lens of control, nonformal learners decide what to learn, but need assistance with how to learn it (Mocker \& Spear, 1982). For example, farmers in the U.S. may enlist the assistance of university extension agents to learn to improve crop production, but agents may provide assistance through the provision of pre-planned materials and activities (Mocker \& Spear, 1982). Literacy programs in developing nations qualify as non-formal learning (Merriam \& Caffarella, 1999), and learning outside of school is generally considered non-formal from 
an international perspective (Mocker \& Spear, 1982). The line between learning contexts is blurry and organizations that deliver formal instruction may also provide non-formal learning opportunities in the community (Merriam \& Caffarella).

Nuanced differences exist in the literature regarding informal learning. Marsick and Watkins (2001) equated informal learning to incidental learning. Merriam and Caffarella (1999) used the terms informal and self-directed learning interchangeably, due to the similarity of these contexts regarding setting and learner control. Mocker and Spear (1982) explained the difference between informal learning and non-formal learning by what learners are able to control about the experience. However, there is agreement adults do not always recognize they are learning when in the midst of informal learning activities (Marsick \& Watkins, 2001; Merriam \& Caffarella, 1999). Informal learning occurs across a variety of cultural, institutional, community, and family settings. Triggered by everyday experiences, the informal learning cycle is always in process, moving through or about various stages of action, interpretation, assessment, and framing of lessons learned. Mistakes and a natural process of trial and error are examples of informal learning (Marsick \& Watkins, 2001).

Informal learning is also intentional (Marsick \& Watkins, 2001). It includes more than reading a book; the Internet, worldwide collaboration through electronic media, and computer simulation are also resources for informal learners in the digital age (King, 2010). For instance, patients who learn for the purpose of contributing to their own care may collect and interpret information from the Internet, health care providers, and support organizations. Hobbyists who read trade publications, practice their craft, and network with others are also informal learners. Informal learners choose how and when 
to access institutional resources to support their varied interests (Merriam \& Caffarella, 1999). Marsick and Watkins (2001) viewed informal learning as a contextual framework for a variety of common adult learning activities. "Examples include self-directed learning, networking, coaching, mentoring, and performance planning that includes opportunities to review learning needs" (Marsick \& Watkins, 2001, pp. 25-26).

\section{Self-Directed Learning}

"Although learning on one's own is the way most adults go about acquiring new ideas, skills, and attitudes, this context has often been regarded as less important than learning that takes place in more formal settings" (Merriam et al., 2007, pp. 79-80). Mocker and Spear (1982) described self-directed learning as a full step removed from informal learning toward near-total learner control over how and what is learned. The authors asserted self-directed learners have full control over what is to be learned (learning objectives) and how it is to be learned (means). Caffarella (1993) identified three perspectives of self-directed learning: (a) a self-initiated process, (b) autonomous learners, and (c) more learner control in formal environments. Merriam (2001) observed three similar goals in the literature for self-directed learning: (a) the humanistic philosophy self-directed learning should develop the capacity of adult learners to become self-directed, (b) to promote transformational learning relying on reflection, and (c) the "promotion of emancipatory learning and social action" (p. 9).

Tough (1978) compared self-directed learning to the $80 \%$ of an iceberg lurking beneath the water's surface. Professionally planned learning projects above the waterline are easy to see, but the hidden bulk of adult learning demands greater attention by adult 
educators. Tough (1978) asserted more than $70 \%$ of major adult learning efforts are selfdirected; purposeful attempts to obtain new knowledge, abilities, or other change.

The learner has a task to perform-raising a child, writing a report for the boss, handling a case, teaching a class, fixing or improving something around the home, sewing a dress-and wishes to learn how to perform a task successfully. (p. 11) Learning projects take at least 7 hours of the learner's time and are comprised of a string of learning episodes. "Any method can be included-reading, listening, observing, attending class, reflecting, practicing, getting answers to questions - as long as the person's primary intention during the learning episode was to gain and retain a defined area of knowledge and skill" (Tough, 1978, p. 9).

The literature frequently referenced Tough's (1978) study of self-planned learning projects (Caffarella, 1993; Cross, 1978; Merriam, 2001). Tough (1978) indicated between 70 and $100 \%$ of respondents participated in at least one major learning activity in the year prior to being interviewed.

Adults spend a remarkable amount of time each year at their major efforts to learn. In fact, a typical learning effort requires 100 hours. The typical adult conducts five of them per year, altogether spending 500 hours on major learning efforts. (Tough, 1978, p. 9)

Tough's (1978) review of the literature indicated differences among participation in adult education by population. However, there was no difference among populations regarding the number of hours spent on self-directed learning initiatives, only number of projects.

Penland (1977) conducted a national study of adults who design and conduct their own learning activities. He indicated continuous learners comprise almost $80 \%$ of the 
population and includes those who planned their own learning, and/or participated in formal and non-formal learning. Learning projects included art, business, religion, English, history, home repairs, relationships, health, and mechanics. Penland explained adults may seek outside resources to assist in self-planned learning, but retain responsibility for the learning. He found adults prefer to conduct their own learning at home, followed by on the job. He also identified preferred methods of learning among adults. One respondent indicated a preference for learning on the job with an experienced mentor, while another preferred to reference books at times (Penland, 1977).

\section{Experience}

A theme familiar to learning in adulthood is the role of learner experience (Knowles, 1984; Kolb, 1984; Merriam \& Brockett, 2007; Merriam \& Caffarella, 1999). "The idea of experience as a core aspect of adult learning is so pervasive in the theory and practice of adult education that it would be difficult to find examples that do not address the role of experience" (Merriam \& Brockett, 2007, p. 153). The importance of experience to learning and education was established by John Dewey (1938) in the early $20^{\text {th }}$ century. Dewey explained experience and education are intrinsically connected, particularly if education is to provide significant meaning to the learner. To recognize the role of learner experience in education and use experience in learning activities is to promote education capable of changing with societal needs (Dewey, 1938).

According to Knowles (1984), Dewey's (1938) educational philosophy was related to children but inspired Eduard Lindeman to apply a similar philosophy to the needs of adult learners. Lindeman (1926) indicated education is equivalent to life and vice versa. Further, adult education is only limited by the extent of adulthood; adulthood 
is not necessarily a starting point. Adult education comes through the requirements of life circumstances and revolves around the responsibilities of adulthood (Lindeman, 1926). Lindeman's (1926) use of the term adult education appeared to mean learning in adulthood, rather than the instruction of adults referred to by Cross (1978). Lindeman (1926) acknowledged academic knowledge may be applied to life circumstances, but generally as one contribution to problems requiring greater intelligence. The greatest resource to adult learners is experience (Lindeman, 1926).

"In its simplest form, experiential learning means learning from experience by doing" (Lewis \& Williams, 1994, p. 5). Cantor (1995) observed experiential learning is both a natural learning process and a method of instruction. Science laboratory activities and internships are examples of experiential learning in higher education (Cantor, 1995). As institutions of higher learning have evolved to include open enrollment policies, the need has correspondingly increased to make learning relevant to life (Kolb, 1984). "Similarly, as the population in general grows older and the frequency of adult career change continues to increase, the 'action' in higher education will be centered around adult learners who demand that the relevance and application of ideas be demonstrated and tested against their own accumulated experience and wisdom" (p. 6).

\section{Prior Learning Assessment}

\section{Background}

By the late 1960s, an increasing number of older returning college students desired college credit for the things they already knew (Keeton, 2000). During the 1970s, prior learning assessment (PLA) was an integral part of the democratization movement, which emphasized increased access to higher education, especially for adult learners 
(Michelson \& Mandell, 2004). The recognition of prior learning by older college students was a matter of equity, since it does not matter where college level learning is obtained (Keeton, 2000). Awarding college credit for prior learning acknowledges learning takes place in a variety of settings (Field, 1993). The demand for qualified workers after World War II, the movement of higher education from a luxury to a necessity for many, an influx of women into higher education, changing college student demographics, and cultural changes, were some of the reasons for a growing interest and movement toward PLA in higher education (Field, 1993; Keeton, 2000).

PLA allows college credit to be awarded for college level learning obtained outside of higher education (Freed \& Mollick, 2009; Hoffman, 2006; Klein-Collins \& Hain, 2009). PLA credits are awarded for the equivalence of learning outcomes, not for the time or effort it took to learn the material (Klein-Collins et al., 2010). Depending on the institution of higher learning, credit may be awarded for prior learning in a number of ways. Credit by examination is one method (Lamdin, 1997). The College Level Examination Program (CLEP) and Defense Activity for Non-Traditional Educational Services (DANTES) are common credit by examination programs (Klein-Collins \& Hain, 2009). Credit for the completion of evaluated programs is another way prior learning is assessed (Klein-Collins, 2011; Lamdin, 1997). For example, the American Council on Education (ACE) evaluates workplace training and makes credit recommendations for consideration by institutions of higher learning (Klein-Collins, 2011; Lamdin, 1997). Learning obtained through experience is often evaluated through the creation and assessment of PLA portfolios (Klein-Collins \& Hain, 2009). 


\section{PLA Methods}

Credit by Examination. College course credit may be awarded for prior learning based on student performance on examinations (Donlon, 1991; Klein-Collins et al., 2010). Examinations used to assess subject-related learning may be similar to the final examinations used to evaluate typical college students (Klein-Collins et al., 2010). However, the main difference between traditional college students and students who earn credit for learning obtained outside the institution, is traditional students must work through a set of activities before taking key course exams (Donlon, 1991). "Thus, the most accurate language for the concept today would be credit-by-examination only, reflecting the fact credit is awarded for a successful, meets the criterion performance regardless of what manner of preparation was used" (Donlon, 1991, p. 2). Donlon's (1991) point notwithstanding, the term credit by examination is used throughout this document to describe prior learning assessed through standardized examinations.

According to Donlon (1991), the first modern utilization of credit by examination can be traced to the University of London in 1836 . In place of classroom courses, the institution examined external students, or students who believed they had obtained university level knowledge without the assistance of the university. Many examinations have been constructed and implemented to evaluate learning obtained outside of the traditional college classroom (Lamdin, 1997). Institutions generally administer customized examinations for institutional or departmental purposes, or nationally recognized standardized examinations (Klein-Collins et al., 2010). The Advanced Placement Program (AP) for incoming college freshmen and the Graduate Record Examinations (GRE) for incoming graduate students are examples of standardized 
examination programs (Lamdin, 1997). Historically, institutions of higher learning have also permitted advanced placement for students through the use of customized departmental examinations (Ozaki, 1978).

The Educational Testing Service (ETS) created the College Level Examination Program (CLEP) for The College Board in 1965 (Beaver \& Paul, 2007). The College Board intended to provide students an exemption for college level studies where competency could be established by examination (Beaver \& Paul, 2007). As a result, CLEP is now the most common means of assessing prior learning (Lamdin, 1997) and credit is awarded for CLEP scores at 2,900 colleges and universities (The College Board, 2011). According to Beaver and Paul (2007), "approximately 200,000 CLEP exams are administered at 1,300 testing centers across the nation" (p. 13) on an annual basis. There are 33 separate CLEP examinations under the five topics of composition and literature, world languages, history and social sciences, science and mathematics, and business (The College Board, 2011). CLEP helps students save time and money, freeing them to focus on higher level courses (The College Board, 2011).

CLEP participants include traditional-age college students, but over half are older than the age of traditional students (The College Board, 2010). "CLEP examinations cover material taught in courses most students take as requirements in the first two years of college. Many examinations are designed to correspond to one-semester courses, although some correspond to full-year or two-year courses" (The College Board, 2011, n.p.). The lower level college course offerings may be expected to attract both recent high school graduates and older adults returning to school or enrolling in college for the first time (The College Board, 2011). The largest cohort of current CLEP participants is 
older than age 30 , followed by the more traditionally aged cohort of $19-22$ year old students (Beaver \& Paul, 2007). Ozaki (1978) postulated age in itself was not a predictor of success on CLEP exams. Beaver and Paul (2007) agreed, and identified "a significant relationship between extent of prior learning and CLEP success." (p. 18).

College teaching faculty members were initially concerned CLEP would negatively impact academic standards, and students who earned credit for first level courses through CLEP would have difficulty in subsequent courses (Ozaki, 1978). "Some legislators saw CLEP as a way to accelerate graduation; thus reducing cost per student of a college education... [however,] faculty generally questioned the validity of granting college credit on the basis of scores from a general achievement examination" (Legg \& Webb, 1977, p. 5). Donlon (1991) suggested faculty concern over CLEP was due in part to its threat to the educational authority of faculty who typically evaluate student performance. Ironically, CLEP examinations are developed by a committee of faculty members and reviewed by another group of faculty who teach the topic of each examination (Beaver \& Paul, 2007). As a further safeguard, institutions accepting CLEP scores for credit are permitted to establish institutionally specific performance standards (Lamdin, 1997; The College Board, 2010).

Ozaki (1978) observed the lack of analytical literature on the topic of CLEP. Years later, Beaver and Paul (2007) noted the dearth of literature on CLEP since the time CLEP was popularized in the 1970s. Tully's (1977) description of a study of more than 700 Florida vocational education teachers is one example of early literature. The twofold purpose of the grant-funded study was to measure test performance by teacher education level and the impact of CLEP participation on the professional development of 
participant test-takers. The program also tested the notion of credit by examination as a strategy for promoting baccalaureate degree completion among working professionals, because $49 \%$ of study participants (employed vocational teachers) had not earned a baccalaureate degree by the start of the study (Tully, 1977).

A critical assumption behind this professional development program was the vocational teachers probably would not be interested in pursuing higher education given the time since they may have first enrolled in higher education (Tully, 1977). Nevertheless, the Florida teachers demonstrated college-level learning and earned credit through CLEP. According to Tully (1977), 54\% of qualified responses indicated CLEP scores had been used to begin or further participant progress in college study. Further, $56 \%$ of respondents to the follow-up survey found study participation had promoted their professional development in some way. Other indicators also lent support to program success, including statistically significant results for degree attainment and career advancement for those who earned college credit for CLEP scores.

Grandy and Shea (1975) conducted a study to examine the use of CLEP. The survey of 634 institutions had a $95 \%$ response rate. One quarter of respondent institutions were 2-year institutions. Not every institution surveyed used CLEP to award credit; some used the general examinations as a research instrument or for some other purpose. "On the average, three-fourths of the students submitting CLEP General Examination scores receive credit in some area. Of the total number of scores submitted, about $60 \%$ are passing" (Grandy \& Shea, 1975, p. 3). Further, "institutions that have conducted research on the use of the General Examinations have found that the grades of students who receive CLEP credit tend to be equal to or better than the grades of other 
students" (Grandy \& Shea, 1975, p. 3). However, the characteristics of CLEP examinees in this study were unclear, as $75 \%$ of respondent institutions indicated test takers were full-time students. Despite Beaver and Paul's (2007) findings suggesting most CLEP examinees are non-traditional learners, the quantity of full-time students in Grandy and Shea's (1975) study implied a large number of traditional students.

Credit by Evaluated Programs. Credit for the completion of evaluated training programs is another means of assessing prior learning (Klein-Collins et al., 2010). For instance, the American Council on Education (ACE) evaluates military and civilian workplace training and makes credit recommendations for consideration by institutions of higher learning (Klein-Collins et al., 2010; Lamdin, 1997). ACE first recommended college credit for military training obtained during World War II (Keeton, 2000; Lamdin, 1997). According to the ACE website, "the American Council on Education's College Credit Recommendation Service (CREDIT) connects workplace learning with colleges and universities by helping adults gain access to academic credit for formal courses and examinations taken outside traditional degree programs" (American Council on Education, 2011, n.p.). Institutions are not obligated to accept ACE CREDIT recommendations and are free to review ACE student transcripts for college credit according to institutional policies and practices (ACE, 2011).

Northern Virginia Community College (NOVA) referred to credit for evaluated training programs as "credits earned in non-traditional educational/training programs (military, industry, state, and federal government)" (NOVA, 2012, n.p.). The college offered to award college credit for the successful completion of local and nationally evaluated programs. For example, course credit may be awarded in courses such as 
"Introduction to Law Enforcement for the successful completion of the Fairfax County Criminal Justice Academy" (NOVA, 2011). In addition, NOVA's Web-based College Credit through Advanced Standing guide indicated credit may be awarded for military and civilian training evaluated by ACE.

As a growing number of adults across the United States require more postsecondary education, they look to colleges and universities with programs and services to meet their needs. More than 2,000 institutions in the ACE CREDIT College and University network do just that with the recognition of ACE CREDIT recommendations. (ACE, 2012, n.p.)

According to the National Guide to College Credit for Workforce Training (2012), ACE evaluated industry courses by organizations such as the American Bankers Association and the Walt Disney Company. In the case of Disney, ACE CREDIT suggested institutions award three upper baccalaureate level credits for the successful completion of the Disney Hospitality Management Course. Course length, learning outcomes, and modes of instruction were also shared to assist institutions in deciding whether to award credit for closely related business management and administration courses.

The literature regarding ACE CREDIT or similar training evaluation programs appears to be scarce. Telephone and electronic requests to ACE in January 2012 for related literature returned no new leads. ACE CREDIT outcomes appear to be aggregated in the literature discussing the general student benefits for participation in non-specific prior learning assessment (PLA) methods.

Portfolios. Another PLA method is the assessment of student portfolios (Lamdin, 1997). Suopis (2009) explained, "PLA has consistently embraced the student's ability to 
document experiential learning through a critical and reflective analysis that we believe is best rendered through the writing of a portfolio" (p. 125). Others also emphasized the utility of portfolios to assess prior learning obtained through experience (Arnold, 2010; Brown, 2002). Unique as a form of PLA, portfolio development is both a learning process and a means of demonstrating learning (Klein-Collins \& Hain, 2009). PopovaGonci (2009) and Amold (2010) depicted the PLA portfolio as a link between experiential learning and the traditional classroom. Portfolio students not only write about and reflect on the experiential learning they hope will be accepted as college level, they demonstrate how they applied the same knowledge (Murphy, 2007).

Drawing on life experiences, portfolio students are typically adult learners. According to Suopis (2009), the average age of portfolio students at one institution was 37 years and Knowles (1984) suggested experiential learning techniques were best applied to learners with sufficient quantity and variety of experience. However, "many adult students who have not had recent formal academic experiences find it daunting to both 'translate' experiential learning achieved through non-academic sources into specific learning outcomes and to express these outcomes in academic jargon" (PopovaGonci, 2009, p. 43). Portfolio programs normally rely on experiential learning models that seem applicable to portfolio learning, but translating experience into learning is an evolving process (Murphy, 2007).

Depending on institutional philosophy, any number of experiential learning models may be utilized for portfolio development and assessment. David Kolb's (1984) learning model most often provides the theoretical basis for writing and evaluating student portfolios (Brown, 2002; Hoffman \& Michel, 2010). Kolb's (1984) experiential 
learning model described four parts to learning: (a) a concrete experience, (b) reflection on the experience, (c) the extraction of abstract concepts from the experience, and (d) determination of next steps for active experimentation. Sometimes Kolb's theory is used to teach students how to learn what their experiences have taught them, as was the case at Nyack College (Murphy, 2007). Murphy recognized Kolb's learning theory as a natural tool for evaluating student portfolios, supporting the practice of awarding academic credit for college-level learning, not merely student experience.

Portfolios may differ in their components and the way they are evaluated for credit (Brown, 2002). Portfolios are generally aligned with the required learning outcomes of specific college courses (Brown). According to Lamdin (1997), most portfolios share four common elements. These elements are (a) the identification of specific learning the student seeks to have recognized as creditable, (b) a narrative describing the learning experience and how it is connected to student plans, (c) documentation supporting student claims, and (d) a request for a specific amount of college credit. Brown (2002) noted a rarer portfolio format centered less on specific course connections and more on the student's experiences and resultant competencies. In this case, Brown described a portfolio with five components: (a) the introduction, (b) the list of learning experiences, (c) learning assessment, (d) autobiography, and (e) documentation. The difference between the styles of portfolios appears to be student intent to challenge specific courses, versus a more universal evaluation (Brown, 2002).

The PLA portfolio narrative and reflective process helps students make new meaning from life experiences and connect prior learning with the objectives of formal academic courses (Arnold, 2010). According to Arnold, "the narrative process in prior 
learning assessment is a significant and vital learning experience that has begun to move into the mainstream college experience as a powerful pedagogical tool" (2010, p. 47). Many constructivists view stories as critical to making meaning and PLA assumes students come with a unique set of life circumstances and experiences. The portfolio narrative honors this individuality and permits educators to understand the student and the context in which the learning took place. "Those who practice prior learning assessment recognize that real-world problems are valid and powerful sources of learning and that students make new meaning as they develop the narrative that persuades the academic to award credit" (Arnold, 2010, p. 49).

Brown (2002) conducted a qualitative study to describe the perspectives of eight portfolio students on learning through the portfolio process. Study participants were an average of 41 years old and attended the same Miami-based undergraduate institution. Beyond the course credits earned, Brown found improvements in self-knowledge, the value of learning, and general competencies among study participants. In regard to selfknowledge, participants indicated a sense of self-discovery and greater recognition of their accomplishments, contributing to an increased sense of empowerment. Students also increased their recognition of learning in the workplace and the value of mentors in their personal and professional development. The participants also "enhanced communication and organizational skills, and their recognition of the importance of reflection in learning" (Brown, 2002, p. 237). These findings supported Eyler's (2009) observation that experiential learning outcomes are realized through student contribution and reflection, as students contemplate and apply their experience to a broader context. 
Student opportunities for portfolio development and assessment vary by institution and locality. For example, the University Without Walls (UWW) at the University of Massachusetts - Amherst takes an integrative approach (Suopis, 2009). First semester students take a course to develop writing, critical thinking, and research skills (Suopis). Students fulfill a writing requirement and produce experiential learning portfolios in their second semester by successfully completing a course entitled Writing About Experience. Further, "the current UWW PLA process is supported by a series of courses that are designed to support any student area of concentration" (Suopis, 2009, p. 127). Completed portfolios are presented to faculty members with related discipline expertise and evaluated against published standards by a team of faculty members. Adult learners may also take a portfolio development course offered at one of twelve Community College of Vermont (CCV) locations (Klein-Collins et al., 2010). Assessment of Prior Learning is a three-credit course wherein students learn to identify, articulate, and document experiential learning via the PLA portfolio (CCV, 2012). Portfolios are collected and evaluated by the Vermont State Colleges Office of External Programs. The Office of External Programs awards resultant course credits, which students may transfer to any college in the system and any other amenable institutions (CCV, 2012; Klein-Collins et al., 2010). Most portfolio students eventually earn a degree, but there are no residency requirements and students are not required to be enrolled in a degree program (CCV, 2012). The Council for Adult and Experiential Learning (CAEL) recently patterned a national PLA portfolio service after Vermont's model (Klein-Collins, Sherman, \& Soares, 2010). 


\section{Outcomes}

In a 2010 study of 48 institutions of higher learning, the Council for Adult and Experiential Learning (CAEL) discovered PLA students experienced greater success than non-PLA students as measured by time to degree, persistence toward degree for nondegree earners, and graduation rates (CAEL, 2010). For example, PLA community college students who earned between 13 and 24 PLA credits earned an associate degree in 4.5 fewer months on average than students with no PLA credit. Though many students in the study received no degree over a 7-year period, PLA students had generally amassed far more credits toward their degree program than non-PLA students. More important, "PLA students in this study had much higher degree-earning rates than nonPLA students. More than half (56\%) of PLA students earned a postsecondary degree within seven years, while only $21 \%$ of non-PLA students did so" (CAEL, 2010, p. 7). Study results were reported in aggregate, not by specific PLA method.

Expounding on the same study, Klein-Collins (2011) noted higher graduation rates for PLA learners over non-PLA learners in each racial/ethnic group. Hispanic PLA learners earned a bachelor's degree about eight times the rate of Hispanic non-PLA learners $(47 \%$ to $6 \%)$ and an associate degree at about three times the rate of Hispanic non-PLA learners (17\% to 6\%). The difference between White (non-Hispanic) PLA learners and White (non-Hispanic) non-PLA learners was also noteworthy. White (nonHispanic) PLA learners earned a bachelor's degree at more than twice the rate of White (non-Hispanic) non-PLA learners (44\% to $19 \%$ ) and an associate degree at a $4 \%$ greater rate (14\% to $10 \%)$. Klein-Collins (2011) observed time to degree completion and tuition savings for many PLA learners. According to the author, "the findings suggest that PLA 
could be a potentially important strategy for helping underserved or disadvantaged adult populations succeed in completing postsecondary degrees" (Klein-Collins, 2011, p. 4).

\section{PLA in the Community College}

Klein-Collins and Hain (2009) noted the use of portfolio development and assessment increased from $50 \%$ in 1991 to $66 \%$ in 2006 among respondent institutions of higher learning. Despite this growth and the association between PLA students and improved student outcomes, portfolio development and assessment is not offered in as many community colleges as credit by examination or credit for evaluated programs. A study of PLA in community colleges (Brigham \& Klein-Collins, 2010) found 64\% of respondent colleges offered student portfolio assessments, while $82 \%$ considered ACE recommendations (credit for evaluated programs) and 90\% accepted CLEP credit (credit by examination). However, Brigham and Klein-Collins (2010) acknowledged PLA is underutilized at community colleges that purportedly recognize or award PLA credit. Further, although respondents foresaw increasing demand for PLA at their institutions, most institutions had no plans to expand PLA services (Brigham \& Klein-Collins, 2010).

\section{Summary}

Klein-Collins, Sherman, \& Soares (2010) asserted:

Today's learners are not necessarily without college-level knowledge or skills even though many have delayed attending college or not yet completed a degree. They may, for example, have several years of work experience during which they learned through on-the-job training, workshops and company-sponsored training, and leadership or technical responsibilities. They also may be in the military, where they gain a range of other types of learning through formal training, 
informal on-the-job learning, and leadership experience. Further, adults have countless opportunities in their everyday lives for self-directed learning or learning that simply happens from carrying out volunteer work, engaging in hobbies, and other activities. Some of this learning is comparable to college-level instruction. (p. 8)

The scarcity of current literature regarding PLA in the community college suggests PLA program-related decisions may be made without clear understanding of the benefit to adult learners. The literature reviewed for this study highlighted positive outcomes for PLA students and institutions, including improved graduation rates. Studies have examined the benefit of single PLA methods such as credit by examination, but few have attempted to compare outcomes related to multiple PLA methods. PLA studies have also included the graduation rates of learners in higher education, but few have attempted to focus on adult learners in the community college. Data appear scarce regarding adult learner graduation rates in the community college by prior learning assessment status and method. The essential question for community colleges is, "how effectively do we deliver on our mission and make a distinctive impact, relative to our resources?" (Collins, 2005, p. 5). As a result of the current study, policy makers, community college leaders, and adult educators will be enabled to make more effective, data-driven decisions leading to increased graduation rates among adult learners. 


\section{CHAPTER 3 \\ METHODOLOGY}

\section{Introduction}

Given the scope of learning in adulthood, the value of self-directed and experiential learning, the connection between self-directed and experiential learning and prior learning assessment (PLA), and the promise of PLA to enhance student outcomes such as graduation rates, an exploratory study was conducted to investigate a gap in the literature regarding adult PLA learner graduation in the community college. Results from the study will begin to make adult educators, community college leaders, and policy makers especially aware of differences and relationships between PLA methods and graduation, and encourage data-driven decisions that lead to improved graduation rates among adult learners. Results from this foundational study are also expected to encourage further study of adult learner graduation in relation to specific PLA methods, the characteristics of community college PLA students, and the utility of learner experience in community college programming.

The purpose of the quantitative study was to examine adult learner graduation rates by prior learning assessment (PLA) status and method at four U.S. community colleges. The exploratory study tested the statistical significance of differences in graduation rates between adult PLA and non-PLA learners in four U.S. community colleges, tested the statistical significance of differences in graduation rates between adult PLA learners by method, and examined the relationship between adult PLA learner graduation and PLA method. Graduation rate was described as the percentage of students who earned an associate degree within 4 years. Associate degrees include the Associate 
of Arts (A.A), Associate of Science (A.S.), Associate of Applied Science (A.A.S.), and similar 2-year degrees, as typical for U.S. community colleges.

\section{Research Questions}

The study was guided by the following three questions:

1. What is the difference in graduation rates between adult non-PLA learners and adult PLA learners at four U.S. community colleges?

2. What is the difference in graduation rates between adult PLA learners by PLA method at four U.S. community colleges?

3. Is there a relationship between adult PLA learner graduation and PLA method at four U.S. community colleges, controlling for age, gender, and race/ethnicity?

\section{Design}

Despite study limitations or potential resistance to study results by advocates for one PLA method or another, a fundamental gap in the knowledge base required an attempt to develop baseline measures of the impact of PLA methods on adult PLA learner graduation in the community college. The first research question regarding PLA status was largely intended to test the current study of adult learner graduation rates at four U.S. community colleges against the existing literature on PLA in aggregate. The second and third research questions were intended to expand the current knowledge base regarding the effects of PLA by method. The research questions required examination of differences between proportions and the ability of PLA methods to predict group outcomes in the face of potentially confounding variables. 
Notwithstanding imperfect sample distributions, quantitative methods provide for the analysis of calculable data, for the purpose of examining relationships between variables (Creswell, 2009). Therefore, a quantitative methods design was the most appropriate strategy to meet the stated objectives of the three research questions.

Sprinthall (2007) noted two essential quantitative research strategies: experimental and post facto. For time, human subject, and resource considerations, an experimental study design was not possible for this study. Instead, participants were necessarily identified by characteristics they already possessed (relative to PLA status and methods), a practice typical of post facto research (Sprinthall, 2007). Since the data collected already existed, the research strategy for the current study was classified as ex post facto.

\section{Context}

\section{Setting}

From North to South, the four participant U.S. community colleges were located in Connecticut, Maryland, Virginia, and Florida. College identities are considered confidential in this report of the study. For study purposes, the community college in Connecticut was known as College A, the college in Maryland was identified as College B, the college in Virginia as College C, and the college in Florida as College D.

According to College A's website, the college was created by the merger of community and technical colleges in the early 1990s. College A is described as a comprehensive community college with more than 5,000 students enrolled each semester in occupational and university transfer programs. Serving Southeastern Connecticut, the current college website claims more than $43 \%$ of its students are 25 years or older and 
advertises specific services for these non-traditional learners. Featured services include portfolio development and assessment, and credit by examination through CLEP.

According to College B's website, the college was created in 1998 through the merger of what were once three separate community colleges. College B's online Fact Book indicated the Northern Maryland college served the full-time equivalent of 7,457 students during the fall of 2007 and 16,020 students for the entire 2007 fiscal year. The exact percentage of adult students age 25 years or older is unknown, but $33 \%$ were 30 years or older and $55 \%$ were between the ages of 20 and 30 years in 2011 . A search of College B's website revealed a resource for the assessment of prior learning. Several forms of credit by examination are advertised, including nationally known and departmental level examinations. Portfolio assessment is promoted for students with substantial knowledge in an academic discipline and for those with an aversion to testing. College $\mathrm{C}$ features six campuses and is located in the Washington, D.C. suburbs of Northern Virginia. College C's website indicated the college was founded in 1964 as a technical college and began its transformation into a comprehensive community college in 1966 with the creation of the Virginia Community College System. According to the college Fact Book, the college served the full-time equivalent of 32,537 enrolled students during the $2009 / 2010$ academic year. In addition, approximately $53 \%$ of its students were age 25 years and older. College C's current online Advanced Standing guidebook described several ways students may earn credit for prior learning, including credit by examination, ACE recommended credit, and portfolio development/evaluation.

College D was founded in 1967 as a junior college, according to the college website. It became known as a community college a few years later and is now known 
simply as a college. A College D administrator explained the college was recently permitted to begin offering baccalaureate degrees in select technical disciplines; however, College D only offered the associate degree during the time under study. The multicampus college is located in an area of Florida well known for its tourism and citrus industries. College D's online Fact Book indicated almost 31,421 full-time equivalent students were served during the 2010/2011 academic year. In contrast to the other participant colleges, only $30 \%$ of College D's student population was age 25 years or older. A college webpage described portfolio assessment, CLEP, and other PLA methods as "Alternative Ways to Earn Credit" at College D.

\section{Variables}

The first research question was intended to examine whether a statistically significant difference existed in adult learner graduation rates between adult non-PLA learners and adult PLA learners. Adult learners who earned any college credit for any of the PLA methods under study were considered to be PLA learners. The independent variable for this first research question was adult learner PLA status (PLA or non-PLA). PLA status was a categorical variable, as students were simply identified by their membership in either the PLA group or the non-PLA group (Sprinthall, 2007). The dependent variable was adult learner graduation rates. Graduation rates were measured by percentage, a ratio allowing comparisons between group outcomes (Sprinthall, 2007).

The study's second research question was intended to test the existence of a statistically significant difference in graduation rates between adult PLA learners by PLA method. The independent variables for the second research question were adult learner PLA methods. Adult learner PLA methods were identified as belonging to one of four 
categories (Sprinthall, 2007): credit for evaluated programs, credit by examination, portfolio development and assessment, and any combination of these three PLA methods. For reporting purposes, these four PLA categories were labeled as ACE, CLEP, Portfolio, and Combination, respectively. The dependent variable was adult PLA learner graduation rates. Graduation rates were measured by percentage, a ratio allowing comparisons between group outcomes (Sprinthall, 2007).

Evidence supporting statistically significant difference in adult PLA learner graduation rates by PLA method led to a test of relationship between adult learner PLA method and graduation rates. The independent variables for the second research question were adult learner PLA methods as a group. Adult learner age, gender, and race/ethnicity were also introduced as independent and potentially confounding variables. Data on adult learner veteran status was also collected, but excluded from the examination of ex post facto data because the status for most learners in the combined dataset was unknown. The dependent variable was adult PLA learner graduation. Variables and means of analysis for the study's three research questions are outlined in Table 3.1. 
Table 3.1

Variable Table

\begin{tabular}{llll}
$\begin{array}{c}\text { Research } \\
\text { Question }\end{array}$ & Independent Variable & Dependent Variable & Means of Analysis \\
\hline One & $\begin{array}{c}\text { PLA Status (PLA or } \\
\text { non-PLA) }\end{array}$ & Graduation Rates & $\begin{array}{l}\text { Hypothesis Test of } \\
\text { Proportions with } \\
\text { Chi-Square }\end{array}$ \\
Two & PLA Method (ACE, & Graduation Rates & $\begin{array}{l}\text { Hypothesis Test of } \\
\text { Proportions with } \\
\text { Chi-Square }\end{array}$ \\
Three & PLA Method (ACE, & Graduation & Logistic Regression \\
\hline
\end{tabular}

Subjects

\section{Sample}

Non-probability sampling took place at the institutional level. This was appropriate since the population of community colleges actively recognizing or awarding PLA credit was unknown, as was the population of adult PLA learners within U.S. community colleges (Plano, Clark, \& Creswell, 2010). Further, institutional sampling could not be random as eligible college institutional researchers could choose to not participate in the study (Plano et al., 2010). Institutions were intentionally invited from different states to participate in the study. Unintentionally, the four U.S. community colleges to submit testable datasets were located along the East Coast. At least two additional community colleges (also along the East Coast) attempted to participate in the study, but were unable to provide testable datasets.

The ex post facto data were collected as a census sample to ensure a sufficient number of adult PLA learners. There was demographic variety among the 20,229 
anonymous adult learners included in the study. The students ranged in age from 25 to 85 years, with a mean age of 34.30 (Table 4.1 ). Males represented $41.6 \%$ of the population, with $58.2 \%$ learners identified as females (Table 4.2). Students identified as White comprised $47.1 \%$ of the population, Black $20.9 \%$, and Hispanic $15.7 \%$, followed by Asian/Pacific Islanders at $9.5 \%$. Adult learners identified as American Indian/Alaska Natives represented $.8 \%$ of the student population, with the remaining $6 \%$ unidentified by race (Table 4.3 ). Veterans comprised at least $9.3 \%$ of the population, and non-Veterans at least $30.6 \%$. However, $60.1 \%$ were not described in terms of military service.

Sample Size. Census data were collected for both the 2004/2005 and 2005/2006 academic years at each college. Datasets were combined to obtain a testable number of PLA learners, especially those who earned credit through Portfolio and Combination PLA methods. After culling unusable data, a total of 20,229 adult learners remained in the combined dataset along with 1,722 adult PLA learners. Clark and Creswell (2010) recommended at least 30 participants be sampled in studies that examine the potential relationship between variables. The analysis tested data regarding 728 adult learners from College A, including 148 adult PLA learners. Census data from College B included 968 adult learners, including 9 adult PLA learners. College C's sample size was 11,414 with 1,401 adult PLA learners, and College D's total sample was 7,119 with 164 adult PLA learners (Table 3.2). Among adult PLA learners, 73 earned credit through portfolios only, 281 earned credit through CLEP only, 1,291 earned credit through ACE only, and 77 earned college credit through a combination of PLA methods (Table 3.3). 
Table 3.2

Sample Distribution by PLA Status and College

\begin{tabular}{|c|c|c|c|c|c|c|}
\hline & & \multicolumn{4}{|c|}{ College } & \multirow[b]{2}{*}{ Total } \\
\hline & & College A & College B & College C & College D & \\
\hline & non-PLA & 580 & 959 & 10013 & 6955 & 18507 \\
\hline \multicolumn{7}{|l|}{ PLA } \\
\hline Status: & PLA & 148 & 9 & 1401 & 164 & 1722 \\
\hline Total & & 728 & 968 & 11414 & 7119 & 20229 \\
\hline
\end{tabular}

Table 3.3

Sample Distribution by PLA Method and College

\begin{tabular}{|c|c|c|c|c|c|c|}
\hline & & \multicolumn{4}{|c|}{ College } & \multirow[b]{2}{*}{ Total } \\
\hline & & College A & College B & College C & College D & \\
\hline & Portfolio only & 38 & 8 & 27 & 0 & 73 \\
\hline \multicolumn{7}{|l|}{ PLA } \\
\hline \multirow[t]{3}{*}{ Method: } & CLEP only & 9 & 1 & 107 & 164 & 281 \\
\hline & ACE only & 87 & 0 & 1204 & 0 & 1291 \\
\hline & Combination & 14 & 0 & 63 & 0 & 77 \\
\hline Total & & 148 & 9 & 1401 & 164 & 1722 \\
\hline
\end{tabular}

\section{Sampling Procedures}

The Council for Adult and Experiential Learning (CAEL) surveyed 48 institutions of higher learning in 2010 , six of which might be considered comprehensive community colleges. The current study intended to approximate the number of community colleges in the CAEL study. At least 100 community colleges were informally screened for study eligibility. However, few community colleges were found to provide a measurable level 
of portfolio assessment, despite advertising portfolio services on college websites. Approximately three dozen community colleges were contacted concerning participation in the study. E-mail and telephone queries were made to learn the protocol for requesting institutional participation in the study and protocols varied widely by institution.

Procedures for requesting data were followed as described or referenced by institutional researchers or other college administrators. After 6 months of formal query and follow up, Community Colleges A, B, C, and D provided testable datasets.

To ensure a sufficient sample size, census data was requested of participating community colleges for adult learners by PLA status and PLA method. Two cohort samples were requested from eligible community colleges. One cohort represented adult learners from the 2004/2005 academic year and the other from 2005/2006. The minimum target sample size at each participant college was 100 PLA learners and 100 non-PLA learners. As a point of reference, non-PLA learners were expected in much greater numbers than PLA learners. Each college initially provided data in excess of the target sample size. However, due to transcript coding challenges at the college level, College B's largest PLA method category, ACE, was excluded from analysis.

The census samples only included adult learners who were at least 25 years old. The reason is the ages of 24 and 25 years are commonly regarded in the literature as the minimum age for non-traditional adult students (Council for Adult and Experiential Learning \& The National Center for Higher Education Management Systems, 2008; Hadfield, 2003; Stokes, 2006; U.S. Department of Education, 2006). Further, 25 years is well beyond the commonly accepted age range of 18 to 22 years for traditional college students (Stokes, 2006; U.S. Department of Education, 2006). The age 25 years and 
older was intended, as Knowles (1984) suggested, to include a group of learners whose quantity and variety of experience lends itself to experiential learning techniques.

Degree program placement was the second requirement for study inclusion. PLA and non-PLA students may be program placed in certificate programs; but the focus of the study was on associate degree completion rates. Therefore, each participant was at least 25 years of age during the first academic year of his/her cohort (either the $2004 / 2005$ or $2005 / 2006$ academic year) and became associate-degree program placed (declared a major) during the same year. For example, an adult learner belonging to the 2004/2005 cohort would have become program placed and was at least 25 years old sometime during the $2004 / 2005$ academic year. Placement or enrollment in the degree program was the important factor, not type of degree or academic discipline.

The period of time under study was a span of four academic years. Four years is twice the typical 2-year period of time to graduate expected of first-time full-time community college students and is consistent with the latest federal graduation rate reporting requirements (U.S. Department of Education, 2010). Cohort data for the 2004/2005 academic year were requested for PLA and non-PLA students who enrolled in a degree program anytime during the academic year. Similarly, cohort data for the 2005/2006 academic year were requested for PLA and non-PLA students who enrolled in a degree program anytime during the academic year. Student demographic information (age, gender, race/ethnicity, and veteran status) was also requested.

In alignment with the first research question, student samples were identified by adult learner PLA status (PLA or non-PLA students). Students who did not earn college credit through PLA during the time under study were considered non-PLA students. 
Similarly, students who earned credit for a PLA method not under study were also considered non-PLA students for purposes of the current study. Students who earned credit through ACE, CLEP, portfolio assessment, or any combination of these three PLA methods, during the time under study, were considered PLA learners. Identification of PLA learners by type of PLA method (ACE, CLEP, Portfolio, or Combination) permitted the mathematical analysis required of research questions two and three.

\section{Data Collection}

The ex post facto data required for the study were not publicly available. Therefore, the approval and assistance of participant community college research officials was critical to the success of the study. Informal contact with institutional officials was made via e-mail or telephone requests during the spring and summer of 2011. The purpose of these initial contacts was to establish a preliminary list of participant institutions. Formal requests for institutional study participation were made through institutional protocols as required. Once approval was granted for study participation, follow-up communication took place in person or via distance communication technology with participant college stakeholders. Additional colleges were identified and contacted over time as most institutional contact yielded no data. Data collection occurred between September 2011 and January 2012. Collection was extended long enough to secure sufficient samples from four community colleges.

The graduation data needed to answer study research questions were not readily recognizable to most institutional researchers. In some cases, the study researcher, institutional researchers, and student information management systems personnel discussed how the requested data might be identified at each college. For instance, 
students who earned college credit at one institution through portfolio development and assessment were identified through two transcript markers. The first marker was the successful completion of the required portfolio course, indicated by the grade of S (satisfactory) for the student development course, SDV 298. A grade of P (pass) assigned to traditional college courses in subsequent semesters indicated successful course challenges through portfolio assessment. Credit awarded for passing CLEP exam scores was identified as CLEP credit, and ACE recommended credit was listed under "other." Student information system personnel were needed to determine how PLA credit was coded for retrieval from participant college student information management systems.

The design of the current study ensured student confidentiality was provided at the participant institution and anonymity was safeguarded at the student level. Participant colleges are not identified by name in this report. Instead, colleges are referred to by a code name and institutional profiles were developed using publicly available information. At the participant level, the use of ex post facto data ensured no personal contact between the researcher and students. Further, community colleges were asked to exclude identifying information from the requested datasets. In the case where one institution unintentionally provided identifying data, the researcher deleted the student names and numbers from the otherwise valuable dataset.

Institutional researchers from participating community colleges were asked to search their respective databases as appropriate and provide the requested data in an electronic format via e-mail correspondence. Datasets were provided via e-mail in Microsoft Excel ${ }^{\mathrm{TM}}$ spreadsheets. Data were collected even in cases where gender, race/ethnicity, and veteran status were unknown or unavailable. Institutional researchers 
at participant community colleges were asked to provide anonymous (no names, no student identification number) student data in response to the following four queries:

- Please provide a data set of all adult (25 years or older) non-PLA learners (earned no CLEP, ACE, or portfolio credit) who first became associate degree program placed anytime during the 2004/2005 academic year. Please indicate which students met the academic requirements for graduation no later than the 2008/2009 academic year. Where known, please indicate student gender, race, age, and veteran status.

- Please provide a data set of all adult (25 years or older) PLA learners (earned CLEP, ACE, portfolio, or combination) who first became associate degree program placed anytime during the 2004/2005 academic year. Please indicate type of PLA credit earned (CLEP, ACE, portfolio, or any combination) and which students met the academic requirements for graduation no later than the 2008/2009 academic year. Where known, please indicate student gender, race, age, and veteran status.

- Please provide a data set of all adult (25 years or older) non-PLA learners (earned no CLEP, ACE, or portfolio credit) who first became associate degree program placed anytime during the $\mathbf{2 0 0 5 / 2 0 0 6}$ academic year. Please indicate which students met the academic requirements for graduation no later than the 2009/2010 academic year. Where known, please describe each student entry by gender, race, age, and veteran status.

- Please provide a data set of all adult (25 years or older) PLA learners (earned CLEP, ACE, portfolio, or a combination) who first became degree program 
placed anytime during the $\mathbf{2 0 0 5 / 2 0 0 6}$ academic year. Please indicate type of PLA credit earned (CLEP, ACE, portfolio, or any combination) and which students met the academic requirements for graduation no later than the 2009/2010 academic year. Where known, please indicate student gender, race, age, and veteran status.

\section{Data Analysis}

Analysis commenced in February 2012 and IBM SPSS Statistics software version 19 was used to analyze the data. The data were combined and no assumptions of normality were made regarding the distributions of the disparate samples of PLA methods. Although less sensitive to minute differences, nonparametric tests may be used on nominal data without making assumptions regarding the distributions (Sprinthall, 2007). Therefore, non-parametric hypothesis tests of proportions were conducted for research questions one and two, supported by chi-square analysis. Logistic regression was used to answer research question three, because of the binary nature of the dependent variable (no degree or completed degree).

\section{Research Question One}

The null hypothesis stated no statistically significant difference existed in graduation rates between adult learners by PLA status (non-PLA or PLA). A nonparametric hypothesis test of proportions was conducted to examine the graduation rates of adult learners by PLA status. This was conducted in SPSS by selecting Analyze, Descriptive Statistics, and Crosstabs, then selecting desired statistics and cell displays. The dependent variable of graduation (no degree or completed degree) was entered as a crosstab row and the independent variable of PLA status (PLA or non-PLA) was entered 
as a crosstab column. The combined graduation rates for adult non-PLA learners and PLA learners were presented in a contingency table followed by a chi-square test of homogeneity. Effect sizes may be computed in a number of ways appropriate to the sample (Thompson, 2009). SPSS provided the option of using a Phi score as effect size. Confidence intervals were reported for the graduation rates. Statistical significance was reported at the .05 level for the chi-square and Phi score.

\section{Research Question Two}

The null hypothesis stated no statistically significant difference in graduation rates existed between adult PLA learners by PLA method at the four community colleges under study. A nonparametric hypothesis test of proportions was conducted to examine adult PLA learner graduation rates by PLA method. This was conducted in SPSS by selecting Analyze, Descriptive Statistics, and Crosstabs, then selecting desired statistics and cell displays. The dependent categorical variable of graduation (no degree or completed degree) was entered as a crosstab row and the independent categorical variable of PLA method (ACE, CLEP, Portfolio, and Combination) was entered as a crosstab column. The combined graduation rates for adult PLA learners were presented in a contingency table followed by a chi-square test of homogeneity. SPSS provided the option of Cramer's V score as a measure of effect size. Confidence intervals were reported for the graduation rates. Statistical significance was reported at the .05 level.

\section{Research Question Three}

The null hypothesis stated no statistically significant relationship existed between graduation of adult PLA learners and PLA method, controlling for adult learner age, gender, and race/ethnicity, at the community colleges under study. Analysis was 
conducted in SPSS by selecting Analyze, Regression, Binary Logistic, and entering the appropriate dependent and covariate information. Gender, race/ethnicity and PLA method were designated as categorical variables, in order to conduct logistic regression.

The answer to research question three was determined by evaluating two logistic regression models. First, Model 1 tested the sole ability of PLA method (categorical independent variable) to predict adult PLA learner graduation (dependent variable) in comparison to the baseline or reduced model produced by the software (Model 0). Next, Model 2 tested the combined ability of PLA method, adult PLA learner age, gender, and race/ethnicity (independent variables), to predict PLA learner graduation (dependent variable) in comparison to Model 1 . Chi-square tests of both models were reported at the .05 level of significance. Wald statistics established the contribution of each independent variable to the model, reported at the .05 level of significance. B scores were also provided as an effect size and to indicate direction of any relationship. HosmerLemeshow Test results were used to indicate the goodness of fit of each model.

\section{Assumptions and Limitations}

The following assumptions and limitations apply to the current study:

- Given the non-experimental nature of the study, findings are not deemed causal. Significant findings are expected to encourage additional study.

- Given the variety of human experience and learning styles, results of the current study should not be used to suggest the value of PLA methods for adult learners beyond implications for graduation. 
- It was presumed program placed students intended to earn an associate degree. It cannot be known whether every student truly intended to earn a degree when program placed.

- It was presumed the data provided by representatives of participating institutions were accurate and inclusive of all student information requested for the study time frames. However, data coding at the institutional level may affect the accuracy of data identification, retrieval, and reporting.

- Participant institution protocols and/or data storage and retrieval systems could not support requests for every data request by PLA method, or for student demographic information.

- It was presumed participant colleges operated on the semester or quarter system. Data were requested for academic years regardless of system. 


\section{CHAPTER 4}

\section{FINDINGS}

\section{Introduction}

The purpose of the exploratory study was to examine adult learner graduation rates by prior learning assessment (PLA) status (PLA and no PLA) and method (ACE, CLEP, and Portfolio) at four U.S. community colleges. Data analyses were designed and conducted to answer the investigative research questions previously asked in Chapter 1 :

1. What is the difference in graduation rates between adult non-PLA learners and adult PLA learners at four U.S. community colleges?

2. What is the difference in graduation rates between adult PLA learners by PLA method at four U.S. community colleges?

3. Is there a relationship between adult PLA learner graduation and PLA method at four U.S. community colleges, controlling for age, gender, and race/ethnicity?

\section{Demographics}

There was demographic variety among the 20,229 anonymous adult learners under study. The students ranged in age (Table 4.1) from 25 to 85 years, with a mean age of 34.30 years. Females represented $58.2 \%$ of the population, while $41.6 \%$ were identified as male (Table 4.2 ). Students identified as White comprised $47.1 \%$ of the population, Black $20.9 \%$, and Hispanic $15.7 \%$, followed by Asian/Pacific Islanders at 9.5\% (Table 4.3). Adult learners identified as American Indian/Alaska Natives were less than $1 \%$ of the student population, with the remaining $6 \%$ unidentified by race. Data regarding veteran status were also collected, but not analyzed due to low response rate. 


\section{Table 4.1}

Adult Learner Age in Years

N 20229

Mean

34.30

Median

31.00

Mode

25

Std. Deviation

9.114

Range

60

Minimum

25

Maximum

85

Table 4.2

Adult Learner Gender

\begin{tabular}{lllll}
\hline \hline & Frequency & $\%$ & Valid \% & Cumulative \% \\
\hline Male & 8421 & 41.6 & 41.6 & 41.6 \\
Female & 11764 & 58.2 & 58.2 & 99.8 \\
Unknown & 44 & .2 & .2 & 100.0 \\
Total & 20229 & 100.0 & 100.0 & \\
\hline \hline
\end{tabular}




\section{Table 4.3}

Adult Learner Race/Ethnicity

\begin{tabular}{lllll}
\hline \hline & \multicolumn{1}{c}{ Frequency $\%$} & Valid \% & Cumulative \% \\
\hline White & 9534 & 47.1 & 47.1 & 47.1 \\
Black & 4223 & 20.9 & 20.9 & 68.0 \\
Hispanic & 3184 & 15.7 & 15.7 & 83.7 \\
Asian/Pacific Islander & 1923 & 9.5 & 9.5 & 93.3 \\
$\begin{array}{l}\text { American Indian/ } \\
\text { Alaska Native }\end{array}$ & 156 & .8 & .8 & 94.0 \\
Other or Unknown & 1209 & 6.0 & 6.0 & 100.0 \\
Total & 20229 & 100.0 & 100.0 & \\
\hline \hline
\end{tabular}

\section{Research Question One}

What is the difference in graduation rates between adult learners by PLA status at four U.S. community colleges? The null hypothesis stated no statistically significant difference existed in graduation rates between adult learners by PLA status (non-PLA or PLA). A nonparametric hypothesis test of proportions (Table 4.4) was conducted to examine the graduation rates of adult learners by PLA status. The combined degree completion rate for adult non-PLA learners was $11.8 \%$, with a $95 \%$ confidence interval of $11.30 \%$ to $12.25 \%$. The combined graduation rate for adult PLA learners was $28.4 \%$, with a $95 \%$ confidence interval of $26.28 \%$ to $30.60 \%$. The chi-square test statistic of 381.701 strongly supported rejection of the null hypothesis with one degree of freedom and was significant at the $p<.05$ level. The Phi score of .137 indicated a weak effect size and was significant at the $p<.05$ level. 
Table 4.4

Adult Degree Completion by PLA Status

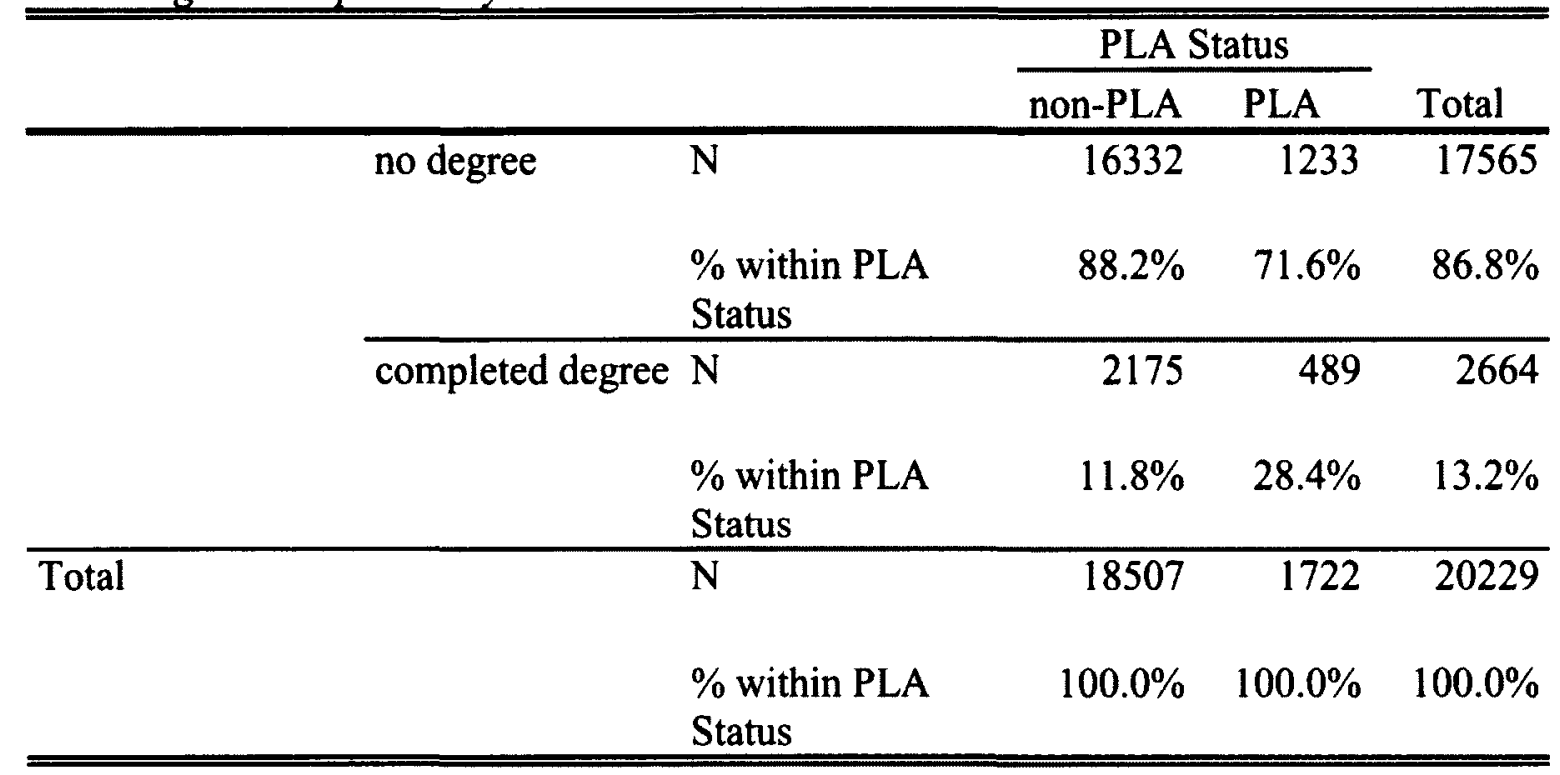

A nonparametric hypothesis test of proportions (Table 4.5) was also conducted to examine the graduation rates (completed degree) of adult learners by PLA status (PLA or non-PLA) and participant college. The test did not control for college, but demonstrated the component graduation rates contained within the answer to research question one. Numbers, rates, and proportions varied widely by college. The chi-square test statistic for College A was 9.967; the chi-square statistic for College B was 5.232, College $\mathrm{C}$ was 201.913, and College D was 369.014. The chi-square test statistics for each college were significant at the $\mathrm{p}<.05$ level. Contingency tables are also available for adult learner age (Appendices A and B), gender (Appendix C), and race/ethnicity (Appendix D). 
Table 4.5

Adult Degree Completion by PLA Status and College

\begin{tabular}{|c|c|c|c|c|c|}
\hline & & & \multicolumn{2}{|c|}{ PLA Status } & \multirow[b]{2}{*}{ Total } \\
\hline & & & non-PLA & PLA & \\
\hline \multirow{4}{*}{ College A } & no degree & $\mathrm{N}$ & 567 & 137 & 704 \\
\hline & & $\begin{array}{l}\% \text { within PLA } \\
\text { Status }\end{array}$ & $97.8 \%$ & $92.6 \%$ & $96.7 \%$ \\
\hline & completed degree & $\mathrm{N}$ & 13 & 11 & 24 \\
\hline & & $\begin{array}{l}\% \text { within PLA } \\
\text { Status }\end{array}$ & $2.2 \%$ & $7.4 \%$ & $3.3 \%$ \\
\hline \multirow[t]{4}{*}{ College B } & no degree & $\mathrm{N}$ & 910 & 7 & 917 \\
\hline & & $\begin{array}{l}\% \text { within PLA } \\
\text { Status }\end{array}$ & $94.9 \%$ & $77.8 \%$ & $94.7 \%$ \\
\hline & completed degree & $\mathrm{N}$ & 49 & 2 & 51 \\
\hline & & $\begin{array}{l}\% \text { within PLA } \\
\text { Status }\end{array}$ & $5.1 \%$ & $22.2 \%$ & $5.3 \%$ \\
\hline \multirow[t]{4}{*}{ College C } & no degree & $\mathrm{N}$ & 8784 & 1032 & 9816 \\
\hline & & $\begin{array}{l}\% \text { within PLA } \\
\text { Status }\end{array}$ & $87.7 \%$ & $73.7 \%$ & $86.0 \%$ \\
\hline & completed degree & $\mathrm{N}$ & 1229 & 369 & 1598 \\
\hline & & $\begin{array}{l}\% \text { within PLA } \\
\text { Status }\end{array}$ & $12.3 \%$ & $26.3 \%$ & $14.0 \%$ \\
\hline \multirow[t]{4}{*}{ College D } & no degree & $\mathrm{N}$ & 6071 & 57 & 6128 \\
\hline & & $\begin{array}{l}\% \text { within PLA } \\
\text { Status }\end{array}$ & $87.3 \%$ & $34.8 \%$ & $86.1 \%$ \\
\hline & completed degree & $\mathrm{N}$ & 884 & 107 & 991 \\
\hline & & $\begin{array}{l}\text { \% within PLA } \\
\text { Status }\end{array}$ & $12.7 \%$ & $65.2 \%$ & $13.9 \%$ \\
\hline Total & & & 18507 & 1722 & 20229 \\
\hline
\end{tabular}




\section{Research Question Two}

What is the difference in graduation rates between adult PLA learners by PLA method at four U.S. community colleges? The null hypothesis stated no statistically significant difference in graduation rates existed between adult PLA learners by PLA method at the four community colleges under study. A nonparametric hypothesis test of proportions (Table 4.6) was conducted to examine adult PLA learner graduation rates by PLA method. The college graduation rate for adult PLA learners who earned Portfolio credit was $12.3 \%$, with a $95 \%$ confidence interval of $5.8 \%$ to $22.12 \%$. The graduation rate for adult PLA learners who earned CLEP credit was $52.3 \%$, with a $95 \%$ confidence interval of $46.30 \%$ to $58.28 \%$. The graduation rate for adult PLA learners who earned ACE credit was $24.0 \%$, with a $95 \%$ confidence interval of $21.70 \%$ to $26.44 \%$. The graduation rate for adult PLA learners who earned credit through more than one PLA method was $29.9 \%$, with a $95 \%$ confidence interval of $20.0 \%$ to $41.38 \%$. The chi-square test statistic of 100.605 supported rejection of the null hypothesis, with three degrees of freedom and was significant at the $p<.05$ level. The Cramer's V of .242 indicated a weak/moderate effect and was significant at the $p<.05$ level. 
Table 4.6

Adult Degree Completion by PLA Method

\begin{tabular}{|c|c|c|c|c|c|c|}
\hline & & Portfolio & CLEP & $\mathrm{ACE}$ & Combination & Total \\
\hline no degree & $\mathrm{N}$ & 64 & 134 & 981 & 54 & 1233 \\
\hline \multicolumn{2}{|c|}{$\%$ within PLA Method } & $87.7 \%$ & $47.7 \%$ & $76.0 \%$ & $70.1 \%$ & $100 \%$ \\
\hline completed degree & $N$ & 9 & 147 & 310 & 23 & 489 \\
\hline \multicolumn{2}{|c|}{$\%$ within PLA Method } & $12.3 \%$ & $52.3 \%$ & $24.0 \%$ & $29.9 \%$ & $28.4 \%$ \\
\hline Total & $\mathbf{N}$ & 73 & 281 & 1291 & 77 & 1722 \\
\hline$\%$ within PLA & Method & $100.0 \%$ & $100.0 \%$ & $100.0 \%$ & $100.0 \%$ & $100.0 \%$ \\
\hline
\end{tabular}

\section{Research Question Three}

Is there a relationship between adult PLA learner graduation and PLA method at four U.S. community colleges, controlling for adult learner age, gender, and race/ethnicity? The null hypothesis stated no statistically significant relationship existed between graduation of adult PLA learners and PLA method, controlling for adult learner age, gender, and race/ethnicity, at the U.S. community colleges under study. Two logistic regression models were created and analyzed to answer research question three. First, Model 1 tested the ability of PLA method (independent variable) to predict adult PLA learner graduation (dependent variable) in comparison to the baseline or reduced model produced by the software (Model 0). Next, Model 2 was used to test the combined ability of PLA method, adult PLA learner age, gender, and race/ethnicity (independent variables), to predict PLA learner graduation in comparison to Model 1. 
Model 1 used PLA method as the group predictor of graduation and produced a chi-square test statistic of 94.290 with three degrees of freedom. The statistic was significant at the $p<.05$ level, supporting rejection of the null hypothesis in the absence of potentially confounding variables. The prediction success (Table 4.7) for PLA method (72.4\% overall, $89.1 \%$ no degree, and $30.1 \%$ completed degree) was more accurate than the constant model (Model 0$)$ selected by the software ( $71.6 \%$ overall, $100 \%$ no degree, and $0 \%$ completed degree). According to the Wald statistic (Table 4.8), Portfolio and CLEP made statistically significant contributions to model prediction $(p<.05)$. The B statistic (log-odds) indicated Portfolio had an inverse relationship with graduation, while CLEP had a positive effect on model prediction. ACE's contribution was not significant and the SPSS software did not expressly include Method 4 (Combination) in the model. The Hosmer-Lemeshow Test statistic was .000 , non-significant at the $p<.05$ level. The non-significant difference between observed and expected test values demonstrated goodness of fit, meaning Model 1 was appropriate for predicting adult learner graduation.

\section{Table 4.7}

Classification Table: Prediction Success for Model 1

\begin{tabular}{|c|c|c|c|c|}
\hline & & \multicolumn{3}{|c|}{ Predicted Degree Completion } \\
\hline & & no degree & $\begin{array}{l}\text { completed } \\
\text { degree }\end{array}$ & $\begin{array}{l}\text { percentage } \\
\text { correct }\end{array}$ \\
\hline & no degree & 1099 & 134 & 89.1 \\
\hline & completed degree & 342 & 147 & 30.1 \\
\hline Overall percentage & & & & 72.4 \\
\hline
\end{tabular}




\section{Table 4.8}

Variables in the Equation for Model 1

\begin{tabular}{lcccccc} 
& B & S.E. & Wald & df & Sig. & $\operatorname{Exp(B)}$ \\
\hline Method & & & 92.932 & 3 & .000 & \\
Portfolio & -1.108 & .434 & 6.507 & 1 & .011 & .330 \\
CLEP & .946 & .276 & 11.737 & 1 & .001 & 2.576 \\
ACE & -.299 & .257 & 1.345 & 1 & .246 & .742 \\
Constant & -.853 & .249 & 11.750 & 1 & .001 & .426 \\
\hline
\end{tabular}

Model 2 used PLA method, age, gender, and race/ethnicity as a combined predictor of adult PLA learner graduation, and produced a chi-square test statistic of 122.224 with ten degrees of freedom. The statistic was significant at the $p<.05$ level, supporting rejection of the null hypothesis. Prediction success for Model 2 (Table 4.9) was $71.9 \%$ overall ( $93 \%$ no degree, and $18 \%$ completed degree) versus $71.6 \%$ overall ( $100 \%$ no degree, and $0 \%$ completed degree) for the constant model (Model 0 ) selected by the statistical software. The Wald statistic (Table 4.10) indicated Portfolio, CLEP, Male, and Black made statistically significant contributions to prediction $(p<.05)$. However, the B statistic (log-odds) indicated CLEP had a positive effect on graduation prediction, while Portfolio, Male, and Black had an inverse effect on PLA learner graduation. The Hosmer-Lemeshow Test statistic was 17.957 , significant at the $p<.05$ level. The significant difference between expected and observed test values indicated Model 2 lacked goodness of fit and was not suited for predicting adult learner graduation. 
Table 4.9

Classification Table: Prediction Success for Model 2

\begin{tabular}{llccc}
\hline & & \multicolumn{3}{c}{ Predicted Degree Completion } \\
\cline { 3 - 4 } & & no degree & $\begin{array}{c}\text { completed } \\
\text { degree }\end{array}$ & $\begin{array}{c}\text { percentage } \\
\text { correct }\end{array}$ \\
\hline Step 1 & no degree & 1150 & 83 & 93.3 \\
& completed degree & 401 & 88 & 18.0 \\
& & & & 71.9 \\
\hline
\end{tabular}

Table 4.10

Variables in the Equation for Model 2

\begin{tabular}{lrrrrr}
\hline Predictor & \multicolumn{1}{c}{ B } & \multicolumn{1}{c}{ Wald } & df & Sig. & Exp(B) \\
\hline Method & & 71.830 & 3 & .000 & \\
Portfolio & -1.240 & 7.815 & 1 & .005 & .289 \\
CLEP & .865 & 9.477 & 1 & .002 & 2.375 \\
ACE & -.293 & 1.266 & 1 & .261 & .746 \\
Age & .006 & .713 & 1 & .399 & 1.006 \\
Male & -.411 & 12.779 & 1 & .000 & .663 \\
Race_N & & 13.620 & 5 & .018 & \\
White & -.220 & .914 & 1 & .339 & .803 \\
Black & -.652 & 6.312 & 1 & .012 & .521 \\
Hispanic & -.232 & .866 & 1 & .352 & .793 \\
Asian/Pacifi & .149 & .262 & 1 & .609 & 1.161 \\
Am Ind/Alas & -.083 & .018 & 1 & .894 & .920 \\
Constant & -.544 & 1.825 & 1 & .177 & .581 \\
\hline
\end{tabular}




\section{CHAPTER 5}

\section{CONCLUSIONS AND RECOMMENDATIONS}

\section{Introduction}

Encouraged by a national completion agenda, an investigative study was conducted regarding adult learner graduation rates in four U.S. community colleges by prior learning assessment (PLA) status (PLA or non-PLA) and method (ACE, CLEP, and Portfolio). The study addressed a gap in the professional literature regarding adult PLA learners in the community college and the relationship between PLA method and graduation. Results for participant colleges confirmed a remarkable difference in graduation rates between adult PLA learners and non-PLA learners, uncovered noteworthy differences in adult learner graduation rates by PLA method, and identified a significant relationship between PLA method and graduation. This final chapter will summarize the impetus for the study, study methodology, results, contributions, and implications for practitioners, decision-makers, and future research.

\section{Study Summary}

\section{Problem Overview}

Much has been written and debated regarding the need for the U.S. to produce more college graduates. One argument is there should be more graduates in proportion to the number of college students. Reasons for increasing the number of graduates include new educational requirements for career success in a knowledge economy and the ability of the U.S. to compete in the global marketplace relative to other developed nations. A number of issues surround the controversial topic of graduation rates. For example, 
whether a college degree is an appropriate academic requirement for many careers and whether every adult should be encouraged to attend college are questions worthy of debate. However, the current study did not address these issues, presuming community college graduation rates could, and should, be improved.

Community college graduation rates are especially low among non-traditional students, learners the literature describes as coping with a variety of adult and family responsibilities. Adults, and adult learners, want to learn what is relevant to their lives and interests. Ironically, adults learn formally and informally on a regular basis, but not always as full-time college students. Given the unique characteristics of adult learners and their growing presence in higher education, it is important to consider ways in which all college-level learning in adulthood (e.g., informal and self-directed) might contribute to degree completion. This should be especially important in the community college, an institution devoted to access and the democratizing effects of higher education.

Prior learning assessment (PLA) offers several methods to evaluate college-level learning obtained outside of community college degree programs, including credit by examination, credit for the completion of evaluated programs, and portfolio assessment. PLA has been utilized in U.S. higher education since World War II, but its many methods have yet to be fully embraced by the modern community college. The literature refers to the benefits of PLA methods in aggregate, but says little about adult PLA learners in the community college and less about the benefits to learners by specific methods.

Therefore, a foundational study was conducted to address a gap in the literature regarding the issues of adult learner graduation rates by PLA method (ACE, CLEP, and Portfolio) and the existence of any relationship between method and graduation. 


\section{Purpose Statement}

The purpose of the quantitative study was to examine adult learner graduation rates by prior learning assessment (PLA) status and method at four U.S. community colleges. The exploratory study tested the statistical significance of differences in graduation rates between adult PLA and non-PLA learners in four U.S. community colleges, tested the statistical significance of differences in graduation rates between adult PLA learners by method, and examined the relationship between adult PLA learner graduation and PLA method. Graduation rate was described as the percentage of students who earned an associate degree within 4 years. Associate degrees include the Associate of Arts (A.A), Associate of Science (A.S.), Associate of Applied Science (A.A.S.), and similar 2-year degrees, as typical for U.S. community colleges.

\section{Research Questions}

The study was guided by the following three questions:

1. What is the difference in graduation rates between adult non-PLA learners and adult PLA learners at four U.S. community colleges?

2. What is the difference in graduation rates between adult PLA learners by PLA method at four U.S. community colleges?

3. Is there a relationship between adult PLA learner graduation and PLA method at four U.S. community colleges, controlling for age, gender, and race/ethnicity?

\section{Review of the Methodology}

Design. The current study focused on the dependent variable of graduation rates in relation to the independent variables of PLA status and method. The first two research questions required the examination of differences between proportions, while the third 
tested the ability of the independent variable to predict the dependent variable, controlling for potentially confounding variables. Creswell (2009) indicated quantitative research methods provide for the analysis of quantifiable data for the purpose of examining relationships between variables. Despite the limitations of the sample distribution(s), a quantitative research design was appropriate to meet the objectives of the three research questions. Sprinthall (2007) noted two essential quantitative research strategies: experimental and post facto. Since the data collected already existed, the specific research design for the current study was ex post facto.

Data Collection. Non-probability sampling was conducted out of necessity and approximately 100 community colleges were informally screened for study eligibility. Telephone and e-mail communication found few community colleges provided a measurable level of portfolio assessment, despite advertising portfolio services on college Web pages. In addition to the first informal screening, approximately three dozen community colleges were directly contacted for potential participation in the study. Queries were made through e-mail and telephone communication to learn the protocol for institutional participation in the study. Procedures for requesting data were followed as prescribed by institutional researchers and other community college administrators. Community Colleges A, B, C, and D provided testable datasets.

The collection of ex post facto data at the institutional level required the participation of institutional researchers at participant colleges. Datasets were requested for all adult learners ( 25 years or older) by PLA status and method for the 2004/2005 and 2005/2006 academic years. The datasets indicated whether the anonymous students met the academic requirements for an associate degree within 4 years and, where known, 
provided student age, gender, race/ethnicity, and veteran status. The data collection process was unique to each college. For example, the primary institutional researcher at College A appeared to have collected the data himself. At College $\mathrm{C}$, the project was approved through the Office of Institutional Research, but student information system personnel were required to cull and decode the necessary data. The disparity between student level data collection by college was a necessary limitation of the study.

Data Analysis. In the early stages of study planning, data type and distribution were presumed to permit parametric testing such as $t$ tests, a one-way analysis of variance (ANOVA), and linear regression. In fact, some parametric testing was conducted as an unofficial point of reference and indicated remarkable results. For example, a Sheffe Post Hoc test indicated stark differences in adult PLA learner graduation rates between specific PLA methods. However, no assumptions of normality were made for the resulting distributions of PLA methods and the binary nature of the dependent variable (completed degree or no degree) made linear regression problematic.

According to Sprinthall (2007), nonparametric tests may be used without assumptions regarding normality of the distributions, although nonparametric tests are less sensitive to minute differences in the data than parametric measures. Therefore, nonparametric tests of proportions were conducted for research questions one and two, supported by chi-square analysis. Logistic regression (also nonparametric) was used to answer research question three. Nonparametric measures were appropriate for this early study of adult PLA learner graduation rates by PLA method. The findings in the current study suggest, however, the need for careful study on a broader scale with more 
generalizable results. Assuming access to richer data, future studies may benefit from parametric measures, or the dual use of parametric and nonparametric methods.

The data were analyzed with IBM SPSS Statistics software version 19. An initial test of frequencies was utilized to describe adult learners in the study by age, gender, race/ethnicity, and veteran status. To answer research questions one and two, hypothesis tests of proportions were conducted to examine the graduation rates of adult learners by PLA status, followed by a separate examination of adult PLA learner graduation rates by PLA method. Each test of proportions was verified with a chi-square test of homogeneity and measure of significance at the .05 level. Two logistic regression models were created and analyzed to answer research question three. First, Model 1 tested ability of PLA method (independent variable) to predict adult PLA learner graduation (dependent variable). Second, Model 2 tested the combined ability of PLA method, adult PLA learner age, gender, and race/ethnicity (independent variables), to predict PLA learner graduation (dependent variable). In addition to model comparisons, the HosmerLemeshow Test was used to indicate the goodness of fit of each model.

\section{Summary of Major Findings}

Research Question One: Graduation Rates by PLA Status. The null hypothesis for research question one was no statistically significant difference would exist in graduation rates between adult learners by PLA status (non-PLA or PLA). A nonparametric test of proportions was conducted to examine the graduation rates of adult learners by PLA status. The combined degree completion rate for adult non-PLA learners was $11.8 \%$, with a $95 \%$ confidence interval of $11.30 \%$ to $12.25 \%$. The combined graduation rate for adult PLA learners was $28.4 \%$, with a $95 \%$ confidence 
interval of $26.28 \%$ to $30.60 \%$. The chi-square test statistic of 381.701 strongly supported rejection of the null hypothesis with one degree of freedom, significant at the $p<.05$ level. The Phi of .137 indicated a weak effect size significant at the $p<.05$ level. In total, analysis confirmed a remarkably higher graduation rate among adult PLA learners than adult non-PLA learners at the four U.S. community colleges under study.

Research Question Two: Graduation Rates by PLA Method. The null hypothesis for research question two was no statistically significant difference would exist in graduation rates between adult PLA learners by PLA method (ACE, CLEP, Portfolio, and Combination) at the four community colleges under study. A hypothesis test of proportions was conducted to examine adult PLA learner graduation rates by PLA method. The college graduation rate for adult PLA learners who earned Portfolio credit was $12.3 \%$, with a $95 \%$ confidence interval of $5.8 \%$ to $22.12 \%$. The graduation rate for adult PLA learners who earned CLEP credit was $52.3 \%$, with a $95 \%$ confidence interval of $46.30 \%$ to $58.28 \%$. The graduation rate for adult PLA learners who earned ACE credit was $24.0 \%$, with a $95 \%$ confidence interval of $21.70 \%$ to $26.44 \%$. The graduation rate for adult PLA learners who earned credit through a Combination of PLA methods was $29.9 \%$, with a $95 \%$ confidence interval of $20.0 \%$ to $41.38 \%$. The chi-square test statistic of 100.605 supported rejection of the null hypothesis with three degrees of freedom and was significant at the $p<.05$ level. The Cramer's $V$ of .242 indicated a weak/moderate effect significant at the $p<.05$ level. According to the analyses, noteworthy differences exist between adult PLA learner graduation rates by method at the colleges under study.

Research Question Three: Relationship between Method and Graduation.

The null hypothesis stated no statistically significant relationship would exist between 
adult PLA learner graduation and PLA method, controlling for adult learner age, gender, and race/ethnicity. Model 1 tested the lone ability of PLA method to predict graduation. Using PLA method as the sole predictor of graduation, a chi-square test statistic of 94.290 supported rejection of the null hypothesis with three degrees of freedom, significant at the $p<.05$ level. The prediction success for Model 1 ( $72.4 \%$ overall, $89.1 \%$ no degree, and $30.1 \%$ completed degree) was higher than the constant model (Model 0 ) selected by the software $(71.6 \%$ overall, $100 \%$ no degree, and $0 \%$ completed degree). The Wald statistic indicated Portfolio and CLEP made significant contributions to model prediction significant at the $\mathrm{p}<.05$ level. Portfolio had an inverse effect, while CLEP had a positive effect on prediction. Despite weak contributions by some PLA methods, the Hosmer-Lemeshow Test (goodness of fit) statistic of .000, insignificant at the $p<.05$ level, indicated Model 1 was appropriate to predict PLA learner graduation. Model 2 tested the ability of PLA method, age, gender, and race/ethnicity as a combined predictor of adult PLA learner graduation. A chi-square test statistic of 122.224 supported rejection of the null hypothesis with ten degrees of freedom and was significant at the $p<.05$ level. Prediction success for Model 2 was $71.9 \%$ overall $(93 \%$ no degree, and $18 \%$ completed degree) versus $71.6 \%$ overall ( $100 \%$ no degree, and $0 \%$ completed degree) for the constant model (Model 0) selected by the statistical software. The Wald statistic indicated Portfolio, CLEP, Male, and Black made statistically significant contributions to prediction, significant at the $p<.05$ level. However, the B statistic (log-odds) indicated only CLEP had a positive effect on graduation prediction. The Hosmer-Lemeshow Test (goodness of fit) statistic of 17.957, significant at the $p<$ .05 level, indicated Model 2 was not appropriate for predicting PLA learner graduation. 
Based on analyses of both logistic regression models, a weak relationship clearly exists between PLA method and adult PLA learner graduation, controlling for age, gender, and race/ethnicity. The relationship, or ability of PLA method to predict graduation, is especially reliant on the inclusion of CLEP in the model developed for the four community colleges under study. This discovery should stimulate further examination of the nature of the relationship between PLA method and graduation.

\section{Findings and the Professional Literature}

According to Brigham and Klein-Collins (2010), PLA was underutilized in one study of community colleges, and students had fewer opportunities to earn credit through portfolios than PLA methods such as ACE or CLEP. Results of the current study appear to align with Brigham and Klein-Collin's observations. Community college websites often indicated students might earn college credit for two or more PLA methods under study. However, further inquiry revealed underutilized or inactive PLA programs, especially in regard to portfolio development and assessment. The data showed a small and uneven use of PLA in general and by specific PLA method. After deleting unusable data, a total of 20,229 adult learners remained in the combined dataset, compared to only 1,722 adult PLA learners. Among adult PLA learners, 1,291 earned credit through ACE only, 281 earned credit through CLEP only, 73 earned credit through portfolio only, and only 77 earned college credit through a combination of PLA methods.

A 2010 study by the Council for Adult and Experiential Learning (CAEL) of 48 post-secondary institutions (including six comprehensive community colleges) reported higher graduation rates for PLA learners than non-PLA students. Klein-Collins (2011) noted higher graduation rates in the CAEL study for PLA learners in each racial/ethnic 
group. In comparison, the current study also found marked differences in the proportion of adult graduates by PLA status. Adult PLA learners graduated at 2.4 times the rate of adult non-PLA learners ( $28.4 \%$ to $11.8 \%$ ) overall. Graduation rates were also higher for adult PLA learners over non-PLA learners by race/ethnicity, particularly for Hispanics. Adult PLA learners identified as Hispanic graduated at almost five times (4.9) the rate of adult non-PLA learners in the same race/ethnicity category (36.6\% to $7.4 \%)$.

Having confirmed significant differences in graduation rates between adult learners by PLA status (PLA or non-PLA), the current study began to examine differences in graduation rates by PLA method. The existing literature seems silent on the relationship of specific PLA methods to adult PLA learner graduation. Community college stakeholders should know if PLA methods have an effect on adult PLA learner graduation rates. The observable difference in adult PLA learner graduation rates by method at four U.S. community colleges was a remarkable new finding (ACE $24.0 \%$, CLEP 52.3\%, Portfolio 12.3\%, and Combination 29.9\%). Further, the discovery of a relationship between PLA method and adult PLA learner graduation was a substantive contribution to the literature. The extraordinary impact of CLEP on model prediction seems to confirm the intuition of the Florida legislators referenced by Legg and Webb (1977) and the degree attainment Tully (1977) observed among vocational teachers.

The current study also presented statistically significant findings and established benchmark effect sizes for every research question. The relative strength of the effect of PLA method on adult PLA learner graduation (Cramer's V .242), in contrast to the omnibus effect of PLA in aggregate on adult learner graduation (Phi .137), was a new finding. Further, the strong positive relationship between CLEP as a PLA method and 
adult PLA learner graduation (log-odds .946) was an important finding, particularly to community college stakeholders seeking promising solutions to the completion agenda. These findings add considerably to the PLA knowledge base, particularly in regard to adult PLA learner graduation in the community college by PLA method. The current study provides a foundation for understanding the utility of PLA, and individual PLA methods, in enhancing adult learner graduation in the community college.

\section{Unexpected Findings}

An unexpected finding of the current study was the lack of a publicly available list of community colleges that currently recognize prior learning for credit. Inquiries to associations and other sources yielded no comprehensive resource. This may be one reason why little was known regarding adult PLA learner graduation in the community college. A second, and perhaps related finding, was the complexity of sampling ex post facto data at the student level. Data retrieval is complicated at some institutions due to institutional methods for coding credit earned through prior learning assessment. For example, PLA credit is often coded the same way as credit transferred from other institutions, making PLA credit identification problematic. Several college representatives indicated their support and interest in the current study, but resource limitations were barriers to identifying and extracting the data as requested.

There were also unanticipated findings among PLA methods. Each PLA method under study generally represented a slightly different type of adult learning. For instance, credit earned for the successful completion of evaluated training (ACE) appears to be the PLA method most similar to college classroom instruction. However, learners who earned ACE credit graduated at a rate of $24 \%$, compared to $11.8 \%$ for adult non-PLA 
learners. Moreover, PLA learners who earned credit for CLEP scores were not expected to graduate at more than twice the rate of ACE learners ( $52.3 \%$ to $24 \%$ ). The remarkably high graduation rate for CLEP learners was surprising because little is known regarding how CLEP examinees learn or prepare for the examinations. Finally, the relatively low graduation rate for Portfolio learners $(12.3 \%)$ was also unforeseen. Portfolios are used to document experiential learning and the literature is generally very positive in regard to the benefits of the PLA portfolio development process.

\section{Conclusions}

\section{Implications for Action}

The current study findings have implications for self-directed learning in adulthood as a means of enhancing adult learner graduation in the community college. Historically, self-directed learning has been considered less essential than formal learning (Merriam et al., 2007), and Donlon (1991) noted relatively little has been done in higher education for the independent learner. However, the graduation rates of adult PLA learners who earned credit for ACE recommendations (24\%), a Combination of PLA methods (29.9\%), and successful CLEP scores (52.3\%), suggest more should be done for adult learners. Results by PLA method revealed a significant link between extracollegiate learning in adulthood and adult learner graduation in the community college.

Several community college stakeholders expressed interest in the current study throughout the periods of study design and data collection. Each stakeholder, from community college presidents to PLA program specialists, wanted to understand the connection between specific PLA methods and adult learner graduation rates in the community college. Although current study results cannot be generalized to all 
community colleges, findings at the community colleges under study lend support to the positive effect of PLA status on adult learner graduation. Based on current study findings, community college leaders may reasonably consider PLA a means of promoting graduation among adult learners and CLEP as an especially promising PLA method.

Innovative leaders should consider ways in which self-directed adult learners might be welcomed, encouraged, and even better prepared to learn and graduate from the community college. This concept is rooted in the philosophy self-directed learning should develop the capacity of adult learners to become self-directed (Merriam, 2001). Educators in formal settings can do more to foster student control (Caffarella, 1993). For example, students may be encouraged to identify and accept responsibility for a specific area of interest within a college course, in addition to the typical learning outcomes. With Knowles'(1984) andragogical assumptions in mind, community college practitioners might screen adult learners for prior learning and assess their developmental level and readiness to learn. Donlon (1991) even suggested exam preparation for adult learners who are good candidates for credit by examination.

Current study results imply adult CLEP learners may have a tremendous advantage over other adult PLA learners at the community colleges under study. This is not to say other PLA methods are not valuable or should be de-emphasized in any way. Nevertheless, the findings suggest CLEP may have extraordinary utility when it comes to promoting community college graduation among adult learners. Until more empirical research is conducted, community college leaders and practitioners should consider lowcost ways of making CLEP tests more accessible to adult learners. For example, college websites might highlight dedicated webpages for adult learners and feature information 
regarding CLEP. In-service training for student advisors might include a job aid and other resources regarding the potential benefits (e.g., timely graduation, cost savings) and limitations (transferability) of earning college credit through CLEP.

\section{Recommendations for Further Research}

Many studies lie ahead in regard to adult learners, PLA, community college graduation, and the completion agenda. The current study should be replicated using a larger institutional sample and parametric/nonparametric measures. National organizations known for improving community college graduation rates might be appropriate sponsors for the future study. Sponsorship could help facilitate the identification and recruitment of participants at the institutional level. Financial and research support could also assist qualified community colleges with data collection. A larger sample should contribute to a normal PLA learner distribution. Results from a larger study should provide a more concrete description of the relationship between PLA method and adult PLA learner graduation.

The current study results should also inspire additional research on the specific utility of CLEP to promote adult PLA learner graduation in the community college. The current study found CLEP data are often easier to collect than ACE and Portfolio data. State community college system offices could be a resource for state-wide data collection, presuming standardized coding and reporting methods for CLEP credit. Research sponsorship would be less necessary for a study of ex post facto data available through central repositories. The participation of a large number of community colleges from many states would provide CLEP data on thousands of students and expand the professional knowledge base on this important means of recognizing prior learning. In 
light of Florida's early adoption of CLEP, a study of the use of CLEP in Florida community colleges could be particularly instructive.

Other future study questions remain to be addressed regarding adult PLA learners and community college graduation. For instance:

- What are the characteristics of successful adult PLA learners in the community college by PLA method?

- What are the institutional barriers to PLA participation among adult students in the community college?

- What are the best practices for promoting adult PLA learner success among high performing community colleges?

- How do successful CLEP examinees prepare for the examinations?

- What successful business practices permit community colleges to provide PLA services for adult learners at scale, while keeping PLA affordable?

\section{Concluding Remarks}

The impetus for the current study was the college completion agenda, or the need to graduate increased numbers of college students. If President Obama's goal of five million additional community college graduates by 2020 is to be achieved and more Americans are to be prepared to participate in the new knowledge economy, adult learners must simply graduate in increasingly higher numbers. However, sizeable increases in adult learner graduation rates are not likely to be realized in the community college without consideration of the unique needs of adult learners. Therefore, the goal of the current study was to begin an investigation of adult learner graduation rates in the 
community college by prior learning assessment (PLA). PLA permits the recognition of adult learning obtained outside the construct of formal higher education.

For the purposes of the current study, each PLA method was presumed to have unique value for specific adult learners, circumstances, and educational goals. The current study did not attempt to evaluate and rank the overall benefit, utility, or value of specific PLA methods. Instead, the current study was a purposeful and early exploration of the potential effect and relationship between PLA status, method, and adult PLA learner graduation in the community college. The current study took an important step toward the potential use of PLA as a means of promoting community college graduation rates among adult learners. Meeting the completion agenda will require further examination of PLA methods and the willingness of community college and PLA stakeholders to advocate for the most effective PLA methods, in regard to graduation.

The current study of adult learner graduation rates in four U.S. community colleges by prior learning assessment status and method succeeded in its purpose. Results confirmed and measured significant difference in graduation rates between adult PLA learners and adult non-PLA learners, uncovered and measured significant difference in the graduation rates of adult PLA learners by PLA method, and identified a significant relationship between PLA method and graduation. As a result of these findings, the current study called attention to the unique needs of adult learners and connected selfdirected college-level learning in adulthood with enhanced community college graduation rates. Findings should provide policy-makers, community college leaders, and adult educators with new insight into adult PLA learners in the community college and a basis for additional research leading to improved graduation among adult learners. 


\section{REFERENCES}

Adams, C. (2010). Obama calls community colleges 'key to future'. Education Week. Retrieved from http://blogs.edweek.org/edweek/college_bound/2010/10/_ community_colleges_are_the.html

American Association of Community Colleges. (2012). American Association of Community Colleges. Retrieved from http://www.aacc.nche.edu/Pages/default. aspx

American Council on Education. (2011). College credit recommendation service (CREDIT). Retrieved from http://www.acenet.edu/Content/NavigationMenu/ Programs Services/CCRS/index.htm

American Council on Education. (2012). ACE CREDIT: The national guide to college credit for workforce training. Retrieved from http://www2.acenet.edu/credit/? fuseaction=browse.main

Arnold, T. (2010). Integrative learning and the individualized prior learning assessment narrative. The Journal of Continuing Higher Education, 58, 47-49. doi:10.1080/07377360903531471

Aud, S., Hussar, W., Kena, G., Bianco, K., Frohlich, L., Kemp, J. (2011). The Condition of Education: 2011. Washington, D.C.: Department of Education, National Center for Education Statistics.

Bailey, T., Crosta, P., \& Jenkins, D. (2006). What can student right-to-know graduation rates tell us about community college performance? New York, NY: Community College Research Center, Columbia University. 
Bailey, T., \& Morest, V. S. (Eds.). (2006). Defending the community college equity agenda. Baltimore, MD: The Johns Hopkins University Press.

Beaver, W., \& Paul, S. T. (2007). The CLEP Program: An evaluation and assessment at a small private university. Mid-Western Educational Researcher, 20(4), 13-20.

Boone, E. (1997). National perspective of community colleges. Community College Journal of Research and Practice, 21, 1-12. doi:10.1080/1066892970210101

Bosworth, B. (2008). The crisis in adult education. Issues in Science and Technology, 24(4), 73-80.

Bragg, D. D. (2001). Community college access, mission, and outcomes: Considering intriguing intersections and challenges. Peabody Journal of Education, 76(1), 93116.

Brigham, C., \& Klein-Collins, R. (2010). Availability, use and value of prior leaming assessment within community colleges. Retrieved from http://www.cael.org/pdf/ PLA_CommunityColleges.pdf

Brown, J. O. (2002). Know thyself: The impact of portfolio development on adult learning. Adult Education Quarterly, 52(3), 228-245. doi: $10.1177 / 0741713602052003005$

Burd, S. (1997, October 3). Should eligibility for U.S. aid be linked to colleges' graduation and retention rates?: State universities hope to fend off an approach that many proprietary schools favor, The Chronicle of Higher Education.

Caffarella, R. S. (1993). Self-directed learning. In S. Merriam (Ed.), An update on adult learning theory. San Francisco, CA: Jossey-Bass Publishers. 
Carnevale, A. P., Smith, N., \& Strohl, J. (2010). Help wanted: Projections of jobs and education requirements through 2016. Retrieved from http://www9.georgetown. edu/grad/gppi/hpi/cew/pdfs/FullReport.pdf

Charles, C. M., \& Mertler, C. A. (2002). Introduction to educational research. Boston, MA: Allyn and Bacon.

Choy, S. (2002). Nontraditional undergraduates. Washington, D.C.: U.S. Department of Education, National Center for Education Statistics, NCES 2002-2012.

Cohen, A. M., \& Brawer, F. B. (2008). The American community college. San Francisco, CA: John Wiley \& Sons, Inc.

Collins, J. (2005). Good to Great and the social sectors: A monograph to accompany Good to Great. New York, NY: Harper Collins.

Community College of Vermont. (2012). Assement of Prior Learning (APL). Retrieved from http://www.ccv.edu/APL

Cooper, M. (2010). Community colleges: Improving America's economic safety net. The Hispanic Outlook on Higher Education, 20(12), 8.

Council for Adult and Experiential Learning. (2010). Fueling the race to postsecondary success: A 48 institution study of prior learning assessment and adult student outcomes. Retrieved from http://www.cael.org/pdf/PLA_Fueling-the-Race.pdf

Council for Adult and Experiential Learning. (2011). Who we are. Retrieved from http://www.cael.org/who_we_are.htm

Council for Adult and Experiential Learning \& The National Center for Higher Education Management Systems. (2008). Adult learning in focus: National and state-by-state data. Retrieved from http://www.cael.org/pdfs/State_Indicators_Monograph 
Creswell, J. W. (2009). Research design: Qualitative, quantitative, and mixed method approaches. Thousand Oaks, CA: Sage Publications, Inc.

Cross, K. P. (1978). The adult learner. Paper presented at the American Association for Higher Education Conference, Washington, D.C.

Delors, J. (1998). Learning: The treasure within. Paris, France: UNESCO Publishing.

Dewey, J. (1938). Experience and education. New York, NY: Kappa Delta Pi; Touchstone (1997).

Donlon, T. F. (1991). The once and future thing: Credit-by-examination in adult education. Paper presented at the Northeastern Educational Research Association, Ellenville, NY.

Dougherty, K. J., \& Townsend, B. K. (2006). Community college missions: A theoretical and historical perspective. New Directions for Community Colleges, 136, 5-13.

Ewell, P. T. (2011). Accountability and institutional effectiveness in the community college. New Directions for Community Colleges, 153, 23-26. doi:10.1002/cc.434

Eyler, J. (2009). The power of experiential education. Liberal Education, Fall 2009, 2431.

Field, M. (1993). APL developing more flexible colleges. New York, NY: Routledge.

Fonte, R. (2011). The community college alternative. Academic Questions, 24, 419-428. doi:10.1007/s12129-011-9255-6

Freed, R., \& Mollick, G. M. (2009). Using prior learning assessment in adult baccalaureate degrees in Texas. Journal of Case Studies in Accreditation and Assessment, 1-14. 
Gilroy, M. (2010). Big plan targets college graduation rates. The Hispanic Outlook on Higher Education, 20(8), 20-21.

Gonzales, J. (2011, February 28). Community-college summit focuses on preparing adult learners for careers, The Chronicle of Higher Education. Retrieved from http://chronicle.com/article/Community-College-Summit/126542/

Gordon, H. R. D. (2003). The history and growth of vocational education in America. Long Grove, IL: Waveland Press, Inc.

Grandy, J., \& Shea, W. M. (1975). The CLEP general examinations in American colleges and universities. New York, NY: College Entrance Examination Board.

Hadfield, J. (2003). Recruiting students and retaining adult students. New Directions for Student Services, 102, 17-25.

Hoerner, J. L. (1970). An historical review of liberal education. Coral Gables, FL: Miami University. Retrieved from http://www.eric.ed.gov/PDFS/ED050677.pdf

Hoffman, T. (2006). Developing assessment rubrics for PLA courses. The Journal of Continuing Higher Education, 54(3), 58-61.

Hoffman, T., \& Michel, K. (2010). Recognizing prior learning assessment best practices for evaluators: An experiential learning approach. The Journal of Continuing Higher Education, 48, 113-120. doi:10.1080/07377361003785132

Horn, L., \& Nevill, S. (2006). Profile of undergraduates in U.S. postsecondary institutions: 2003-04. With a special analysis of community college students, NCES 2006-184. Washington, DC: National Center for Education Statistics, U.S. Department of Education. 
Ignash, J. M., \& Townsend, B. K. (2001). Statewide transfer and articulation policies: Current practices and emerging issues. In B. K. Townsend \& S. B. Twombly (Eds.), Community colleges: Policy in the future context (pp. 173-192). Westport, CT: Ablex Publishing.

Jaschik, S. (2010, April 19). The completion agenda. The Chronicle of Higher Education. Retrieved from http://www.insidehighered.com/news/2010/04/19/completion Keeton, M. T. (2000). Recognizing learning outside of schools in the United States of America. In N. Evans (Ed.), Experiential learning around the world. Philadelphia, PA: Jessica Kingsley Publishers.

King, K. P. (2010). Informal learning in the virtual era. In C. E. Kasworm, A. D. Rose, \& J. M. Ross-Gordon (Eds.), Handbook of Continuing Education (2010 ed., pp. 421429). Thousand Oaks, CA: SAGE Publications, Inc.

Klein-Collins, R. (2011). Underserved students who earn credit through Prior Learning Assessment (PLA) have higher degree completion rates and shorter time-todegree. Chicago, IL: The Council for Adult and Experiential Learning.

Klein-Collins, R., \& Hain, P. (2009). Prior learning assessment: How institutions use portfolio assessments. The Journal of Continuing Higher Education, 57, 187-189. doi:10.1080/07377360903263935

Klein-Collins, R., Sherman, A., \& Soares, L. (2010). Degree completion beyond institutional borders: Responding to the new reality of mobile and nontraditional learners. Retrieved from http://www.americanprogress.org/issues/2010/10/degree _completion_beyond_borders.html 
Knowles, M. (1984). The adult learner: A neglected species. Houston, TX: Gulf Publishing Company.

Knudson, E. (2004). Linking Gateway Technical College with workforce development: The SC Johnson - a family company story. Community College Journal of Research and Practice, 28, 5-16.

Kolb, D. A. (1984). Experiential learning: Experience as the source of learning and development. Upper Saddle River, NJ: Prentice Hall PTR.

Laanan, F. S. (2001). Accountability in community colleges: Looking toward the 21 st century. In B. Townsend \& S. Twombly (Eds.), Community colleges: Policy in future context (pp. 57-76). Westport, CT.: Ablex Publishing.

Lamdin, L. (1997). Earn college credits for what you know. Dubuque, IA: Kenndall/Hunt Publishing Company.

Legg, S. M., \& Webb, J. N. (1977). The impact of the college level examination program: A four-year study. Gainesville, FL: The University of Florida. Retrieved from http://www.eric.ed.gov/PDFS/ED167599.pdf

Levine, A. (2001). Higher education as a mature industry. In P. Altbach, P. Gumport, \& D. Johnstone (Eds.), In defense of American higher education (pp. 38-58). Baltimore, MD: The Johns Hopkins University Press.

Lewis, L. H., \& Williams, C. J. (1994). Experiential learning: Past and present. San Francisco, CA: Jossey-Bass Inc.

Lindeman, E. C. (1926). The meaning of adult education. New York, NY: New Republic. 
Marsick, V. J., \& Watkins, K. E. (2001). Informal and incidental learning. In S. B. Merriam (Ed.), Update on adult learning theory: New directions for adult and continuing education. San Francisco, CA: Jossey-Bass.

Mellow, G. O., \& Heelan, C. (2008). Minding the dream: The process and practice of the American community college. Lanham, MD: Rowman \& Littlefield Publishers, Inc.

Merriam, S. B. (2001). Adragogy and self-directed learning; Pillars of adult learning theory. In S. Merriam (Ed.), The new update on adult learning theory. San Fancisco, CA: Jossey-Bass.

Merriam, S. B., \& Brockett, R. G. (2007). The profession and pratice of adult education: An introduction. San Francisco, CA: Jossey-Bass.

Merriam, S. B., \& Caffarella, R. S. (1999). Learning in adulthood: A comprehensive guide. San Francisco, CA: Jossey-Bass, Inc.

Merriam, S. B., Caffarella, R. S., \& Baumgartner, L. M. (2007). Learning in adulthood: A comprehensive guide. San Francisco, CA: Jossey-Bass, Inc.

Michelson, E., \& Mandell, A. (2004). Introduction. In E. Michelson \& A. Mandell (Eds.), Portfolio development and the assessment of prior learning (pp. 1-19). Sterling, VA: Stylus Publishing, LLC.

Mocker, D. W., \& Spear, G. E. (1982). Lifelong learning: Formal, nonformal, informal, and self-directed. Columbus, OH: ERIC Clearinghouse on Adult, Career and Vocational Education. 
Mullin, C. M. (2010). Rebalancing the mission: The community college completion challenge (Policy Brief 2010-02PBL). Washington, DC: American Association of Community Colleges.

Murphy, E. J. (2007). A review of Bloom's taxonomy and Kolb's theory of experiential learning: Practical uses for prior learning assessment. The Journal of Continuing Higher Education, 55, 64-66.

National Center for Education Statistics. (2010). NCES Digest of Educational Statistics, 2010. Retrieved from http://nces.ed.gov/programs/digest/d10/tables/dt10_423.asp ?referrer=report

Nomi, T. (2005). Faces of the future: A portrait of first-generation community college students. Washington, DC: American Association of Community Colleges.

Northern Virginia Community College. (2011). Advanced Standing Committee Meeting Minutes, April 25, 2011. Retrieved from http://www.nvcc.edu/aboutnova/directories--offices/administrative-offices/academic/committees/advanced/ minutes/Advanced-Standing-Minutes-2011-4-25.pdf

Northern Virginia Community College. (2012). Advanced Standing. Retrieved from http://www.nvcc.edu/about-nova/directories--offices/administrativeoffices/academic/advanced/index.html

Ozaki, R. H. (1978). CLEP students compared to non-CLEP students in the community college [microform]. ERIC Clearinghouse.

Penland, P. R. (1977). Self-planned learning in America. Final report. Washington, D.C.: Bureau of School Systems, Library Research and Demonstration Branch. 
Plano Clark, V. L., \& Creswell, J. W. (2010). Understanding research: A consumer's guide. Upper Saddle River, NJ: Pearson Education, Inc.

Popova-Gonci, V. (2009). All work and no PLA makes Jack a dull boy. The Journal of Continuing Higher Education, 57, 42-44.

Pratt, D. D. (1993). Andragogy after twenty-five years. In S. Merriam (Ed.), An update on adult learning theory (pp. 15-23). San Francisco, CA: Jossey-Bass.

Pub. L. No. 89-329. (1965). Higher Education Act of 1965.

Pub. L. No. 101-542. (1990). Student Right-to-Know and Campus Security Act.

Pusser, B., Breneman, D., Gansneder, B., Kohl, K., Levin, J., Milam, J. (2007). Returning to learning: Adults' success in college is key to America's future. Indianapolis, IN: Lumina Foundation for Education. Retrieved from http://www.luminafoundation. org/publications/ReturntolearningApril2007.pdf.

Reitano, J. R. (1998). The community college mission: Access or anarchy? Community Review, 16119, 119-127.

Ritt, E. (2008). Redefining tradition: Adult learners and higher education. Adult Learning, 19(1-2), 12-16.

Runningen, R., \& Johnston, N. (2010). Obama calls U.S. community colleges 'unsung heroes', Business Week. Retrieved from http://www.businessweek.com/news/2010 -10-05/obama-calls-u-s-community-colleges-unsung-heroes-.html

Shaw, K. M. (2001). Reframing remediation as a systemic phenomenon: A comparative analysis of remediation in two states. In B. Townsend \& S. Twombly (Eds.), Community colleges: Policy in the future context (pp. 193-221). Westport, CT: Ablex Publishing. 
Sprinthall, R. C. (2007). Basic statistical analysis. Boston, MA: Allyn and Bacon.

Stokes, P. J. (2006). Hidden in plain sight: Adult learners forge a new tradition in higher education. Retrieved from http://www2.ed.gov/about/bdscomm/list/hiedfuture/ reports/stokes.pdf

Suopis, C. A. (2009). Changing PLA processes, not PLA. The Journal of Continuing Higher Education, 57, 125-128. doi: 10.1080/07377360902984853

Templin, R. (2011). America's community colleges: The key to the college completion challenge? The Presidency, The American Council on Education Magazine for Higher Education Leaders, Special Supplement, 7-9.

The College Board. (2010). Who takes CLEP? Retrieved from http://clep.collegeboard.org/develop/programs

The College Board. (2011). College Level Examination Program (CLEP). Retrieved from http://clep.collegeboard.org/

Thompson, B. (2009). Computing and interpreting effect sizes in educational research. Middle Grades Research Journal, 4(2), 11-24.

Tough, A. (1978). Major learning efforts: Recent research and future directions. In K. Cross, A. Tough \& R. Weathersby (Eds.), The adult learner (pp. 9-18). Washington, D.C.: American Association for Higher Education.

Tully, G. E. (1977). Credit by examination and professional development of vocational education teachers. Journal of Vocational Education Research, 2(3), 41-47.

U.S. Department of Education. (2006). A test of leadership: Charting the future of U.S. higher education. A report of the Commission appointed by Secretary of 
Education Margaret Spellings, pre-publication copy. Retrieved from

http://www2.ed.gov/about/bdscomm/list/hiedfuture/reports/pre-pub-report.pdf

U.S. Department of Education. (2010). Tracking students to $200 \%$ of normal time: Effect on institutional graduation rates. Retrieved from http://nces.ed.gov/pubs2011/2011221.pdf

UDC Community College. (2012). Workforce Development Program. Retrieved from http://cc.udc.edu/workforce_development

Vaughan, G. B. (2006). The community college story. Washington, DC: Community College Press.

Wang, W. (2004). UCLA community college review: Community education in the community college. Community College Review, 32(3), 43-56.

Zeidenberg, M. (2008). Community colleges under stress. Issues in Science and Technology, 24(4), 53-58. 


\section{APPENDIX A}

\section{ADULT LEARNER DEGREE COMPLETION RATES}

BY PLA STATUS AND SELECT AGES (25, 30, AND 35)

\begin{tabular}{|c|c|c|c|c|c|}
\hline \multirow{2}{*}{\multicolumn{3}{|c|}{ Age in Years }} & \multicolumn{2}{|c|}{ PLA Status } & \multirow{3}{*}{$\begin{array}{c}\text { Total } \\
1988\end{array}$} \\
\hline & & & \multirow{2}{*}{$\begin{array}{l}\text { non-PLA } \\
1881\end{array}$} & \multirow{2}{*}{$\begin{array}{l}\text { PLA } \\
107\end{array}$} & \\
\hline$\overline{25}$ & no degree & $\mathrm{N}$ & & & \\
\hline & & $\%$ within PLA Status & $85.3 \%$ & $73.8 \%$ & $84.6 \%$ \\
\hline & completed degree & $\mathrm{N}$ & 324 & 38 & 362 \\
\hline & & $\%$ within PLA Status & $14.7 \%$ & $26.2 \%$ & $15.4 \%$ \\
\hline \multirow[t]{4}{*}{$\overline{30}$} & no degree & $\mathbf{N}$ & 805 & 77 & 882 \\
\hline & & $\%$ within PLA Status & $89.4 \%$ & $70.6 \%$ & $87.4 \%$ \\
\hline & completed degree & $\mathrm{N}$ & 95 & 32 & 127 \\
\hline & & $\%$ within PLA Status & $10.6 \%$ & $29.4 \%$ & $12.6 \%$ \\
\hline \multirow[t]{4}{*}{$\overline{35}$} & no degree & $\mathrm{N}$ & 498 & 39 & 537 \\
\hline & & $\%$ within PLA Status & $88.3 \%$ & $72.2 \%$ & $86.9 \%$ \\
\hline & completed degree & $\mathrm{N}$ & 66 & 15 & 81 \\
\hline & & $\%$ within PLA Status & $11.7 \%$ & $27.8 \%$ & $13.1 \%$ \\
\hline
\end{tabular}




\section{APPENDIX B}

\section{ADULT LEARNER DEGREE COMPLETION RATES}

BY PLA STATUS AND SELECT AGES (40, 45, AND 50)

\begin{tabular}{|c|c|c|c|c|c|}
\hline \multirow{2}{*}{\multicolumn{3}{|c|}{ Age in Years }} & \multicolumn{2}{|c|}{ PLA Status } & \multirow[b]{2}{*}{ Total } \\
\hline & & & \multicolumn{2}{|c|}{ non-PLA PLA } & \\
\hline \multirow[t]{4}{*}{$\overline{40}$} & no degree & $\mathrm{N}$ & 422 & 22 & 444 \\
\hline & & $\%$ within PLA Status & $90.9 \%$ & $52.4 \%$ & $87.7 \%$ \\
\hline & completed degree & $\mathrm{N}$ & 42 & 20 & 62 \\
\hline & & $\%$ within PLA Status & $9.1 \%$ & $47.6 \%$ & $12.3 \%$ \\
\hline \multirow[t]{4}{*}{$\overline{45}$} & no degree & $\mathrm{N}$ & 262 & 20 & 282 \\
\hline & & $\%$ within PLA Status & $90.3 \%$ & $71.4 \%$ & $88.7 \%$ \\
\hline & completed degree & $\overline{\mathrm{N}}$ & 28 & 8 & 36 \\
\hline & & $\%$ within PLA Status & $9.7 \%$ & $28.6 \%$ & $11.3 \%$ \\
\hline \multirow[t]{4}{*}{50} & no degree & Count & 169 & 19 & 188 \\
\hline & & $\%$ within PLA Status & $91.8 \%$ & $90.5 \%$ & $91.7 \%$ \\
\hline & completed degree & Count & 15 & 2 & 17 \\
\hline & & $\%$ within PLA Status & $8.2 \%$ & $9.5 \%$ & $8.3 \%$ \\
\hline
\end{tabular}




\section{APPENDIX C}

ADULT DEGREE COMPLETION RATES BY PLA STATUS AND GENDER

\begin{tabular}{|c|c|c|c|c|c|}
\hline \multirow{2}{*}{ Gender N } & & & \multicolumn{2}{|c|}{ PLA Status } & \multirow[b]{2}{*}{ Total } \\
\hline & & & non-PLA & PLA & \\
\hline \multirow[t]{4}{*}{ Male } & no degree & $\mathrm{N}$ & 6539 & 771 & 7310 \\
\hline & & $\%$ within PLA Status & $88.3 \%$ & $75.7 \%$ & $86.8 \%$ \\
\hline & completed degree & $\mathrm{N}$ & 864 & 247 & 1111 \\
\hline & & $\%$ within PLA Status & $11.7 \%$ & $24.3 \%$ & $13.2 \%$ \\
\hline \multirow[t]{4}{*}{ Female } & no degree & $\mathrm{N}$ & 9754 & 462 & 10216 \\
\hline & & $\%$ within PLA Status & $88.2 \%$ & $65.6 \%$ & $86.8 \%$ \\
\hline & completed degree & $\mathrm{N}$ & 1306 & 242 & 1548 \\
\hline & & $\%$ within PLA Status & $11.8 \%$ & $34.4 \%$ & $13.2 \%$ \\
\hline \multirow[t]{4}{*}{ Unknown } & no degree & $\mathbf{N}$ & 39 & $\overline{0}$ & 39 \\
\hline & & $\%$ within PLA Status & $88.6 \%$ & & $88.6 \%$ \\
\hline & completed degree & $\mathbf{N}$ & 5 & 0 & $\overline{5}$ \\
\hline & & $\%$ within PLA Status & $11.4 \%$ & & $11.4 \%$ \\
\hline
\end{tabular}




\section{APPENDIX D}

\section{ADULT DEGREE COMPLETION RATES BY PLA STATUS AND}

\section{RACE/ETHNICITY}

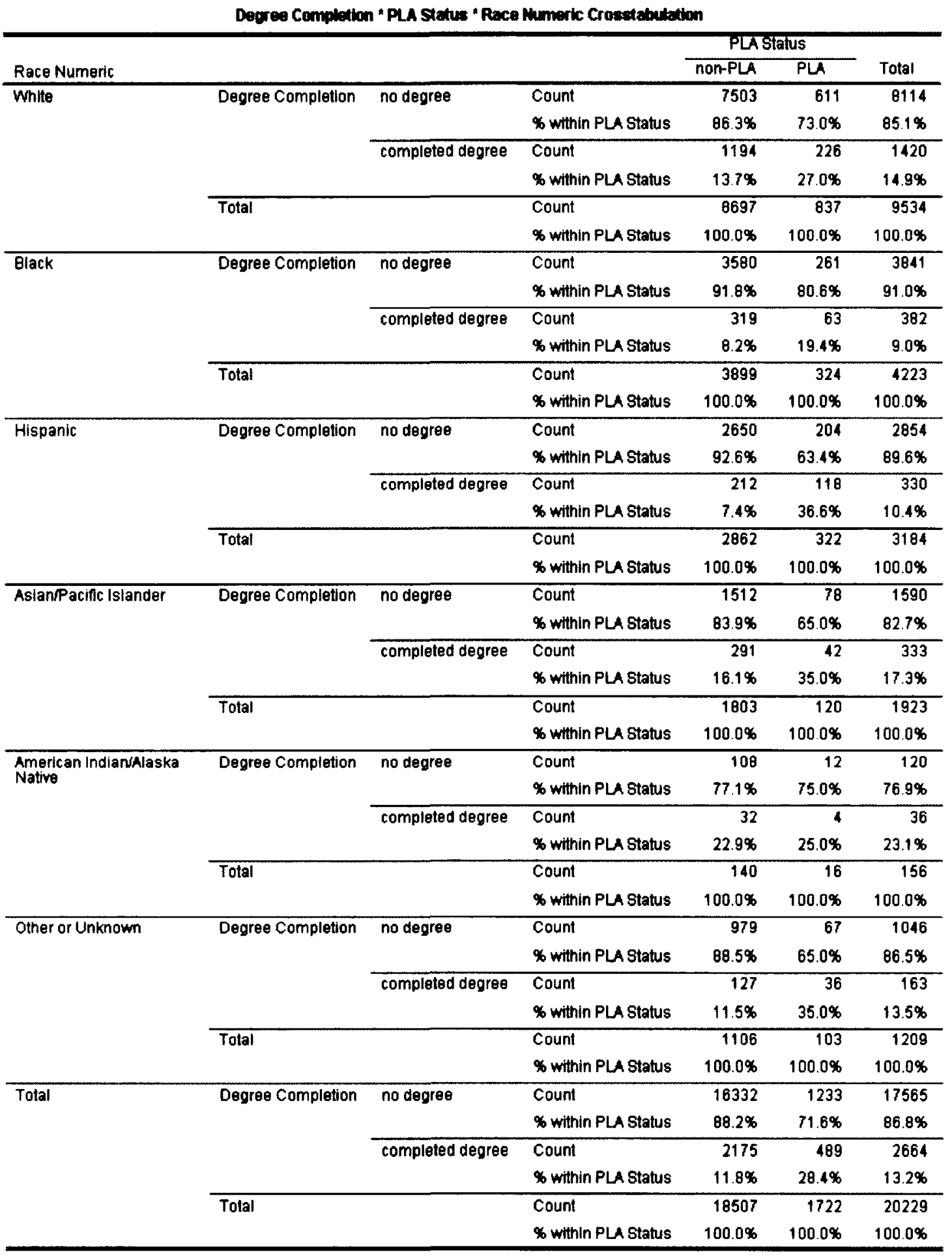


VITA

Recent Professional Experience

Special Assistant Career \& Technical Education (September 2007- Current)

Northern Virginia Community College, Annandale Virginia

Acting Dean of Science and Applied Technologies Division (June 2004- Sept. 2007)

Northern Virginia Community College, Alexandria Campus

Instructor Automotive Technology (January 1998- June 2004)

Northern Virginia Community College, Alexandria Campus.

\section{Formal Education}

Ph.D., Community College Leadership - Old Dominion University, 2012.

M.S., Adult Learning/HRD - Virginia Polytechnic Institute and State University, 2006.

B.S., Management - National-Louis University, 1998.

A.A.S., Automotive Technology - Northern Virginia Community College, 1995.

\section{Recent Presentations}

Co-Presenter - Advanced Standing Task Force Recommendations

Lord Fairfax Community College, August 2011

Presenter - Prior Learning Assessment in the Community College

Virginia Community College System "New Horizons 2011," April 2011

Presenter - CONFINTEA VI (Implications for the Community College)

Virginia Community College System "New Horizons 2010," April 2010

Co-Presenter - NOVA Serves: Developing Students and Community through Service Learning, Northern Virginia Community College Spring Convocation, January 2010

\section{Recent Honors}

Peggy Woofter Hull Scholarship - Old Dominion University, Fall 2011

Chancellor's Faculty Fellowship - Virginia Community College System, 2010/2011

Private Sector Advisor to U.S. Delegation - UNESCO CONFINTEA VI, 2009 